\title{
Heritable epigenetic diversity for conservation and utilization of epigenetic germplasm resources of clonal East African Highland banana (EAHB) accessions
}

\author{
M. Kitavi ${ }^{1,2} \cdot$ R. Cashell ${ }^{1} \cdot$ M. Ferguson ${ }^{2} \cdot$ J. Lorenzen $^{2,3} \cdot$ M. Nyine ${ }^{2} \cdot$ P. C. McKeown ${ }^{1} \cdot$ C. Spillane ${ }^{1}$ (D)
}

Received: 15 July 2019 / Accepted: 20 May 2020 / Published online: 27 July 2020

(c) The Author(s) 2020

\begin{abstract}
Key message Genetically identical East African Highland banana (EAHB) clones are epigenetically diverse with heritable epialleles that can contribute to morphological diversity.

Abstract Heritable epigenetic variation can contribute to agronomic traits in crops and should be considered in germplasm conservation. Despite the genetic uniformity arising from a genetic bottleneck of one ancestral clone, followed by subsequent vegetative propagation, East African Highland bananas (EAHBs) display significant phenotypic diversity potentially arising from somatic mutations, heritable epialleles and/or genotype-by-environment interactions. Here, we use DNA methylation profiling across EAHB accessions representing most of the primary EAHB genepool to demonstrate that the genetically uniform EAHB genepool harbours significant epigenetic diversity. By analysing 724 polymorphic DNA methylation sites by methylation-sensitive AFLP across 90 EAHB cultivars, we could differentiate the EAHB varieties according to their regions (Kenya and Uganda). In contrast, there was minimal association of DNA methylation variation with the five morphological groups that are used to classify EAHBs. We further analysed DNA methylation patterns in parent-offspring cohort, which were maintained in offspring generated by sexual (seed) and asexual (vegetative) propagation, with higher levels of altered DNA methylation observed in vegetatively generated offspring. Our results indicate that the phenotypic diversity of nearisogenic EAHBs is mirrored by considerable DNA methylation variation, which is transmitted between generations by both vegetative reproduction and seed reproduction. Genetically uniform vegetatively propagated crops such as EAHBs harbour considerable heritable epigenetic variation, where heritable epialleles could arise in offspring and contribute to functional traits. This study provides a basis for developing strategies for conservation of epigenetic resources and for integration of epimarkers into crop breeding programmes.
\end{abstract}

Communicated by Reinhard Toepfer.

Electronic supplementary material The online version of this article (https://doi.org/10.1007/s00122-020-03620-1) contains supplementary material, which is available to authorized users.

C. Spillane

charles.spillane@nuigalway.ie

1 Genetics and Biotechnology Lab, Plant and AgriBiosciences Research Centre (PABC), Ryan Institute, National University of Ireland Galway, University Road, Galway H91 REW4, Ireland

2 International Institute for Tropical Agriculture (IITA), P.O. Box 30709-00100, Nairobi, Kenya

3 Crop R\&D, Agricultural Development, Bill \& Melinda Gates Foundation, PO Box 23350, Seattle, WA 98102, USA

\section{Introduction}

Future crop improvement and agricultural productivity increases are reliant on improved harnessing of the genetic diversity within primary crop genepools, and also within the secondary and tertiary genepools of crop wild relatives (Cooper et al. 2001; Halewood et al. 2018). Plant breeding programmes rely on access to crop germplasm resources consisting of elite breeding materials, existing varieties and germplasm accessions from primary crop and wild relative genepools (Castañeda-Álvarez et al. 2016; Rebetzke et al. 2018). Depending on the reproductive and propagation biology of the crop, genetic resources conservation programmes aim to conserve as much phenotypic and genetic diversity as possible in ex situ conservation programmes (e.g. in seed genebanks, in vitro clonal collections or field genebanks). Maximizing both phenotypic and 
genetic diversities represented within genebanks is a key goal for genetic resources conservation, which is enabled by molecular genetic tools, phenotyping (e.g. descriptors) and approaches such as the establishment of core collections (Brozynska et al. 2016; Spillane and Gepts 2001; van Hintum et al. 2000).

Clonally propagated crops, such as East African Highland Bananas (EAHBs), pose particular challenges for crop genetic resources conservation. In such species, clonal propagation, typically via somatic propagules, is used to maintain field genebanks and/or in vitro clonal collections (De Langhe et al. 2016; Engelmann 2011). For many clonally propagated crops, seed-based conservation is difficult due to seed recalcitrance to cold storage, sterility issues due to polyploidy and the difficulty of maintaining stable genotypes using seeds generated by meiosis (Engelmann 2011). East African Highland Bananas (EAHBs), which are sexually sterile triploids, are a major staple crop of importance to food and livelihood security in the Great Lakes region of East Africa and are commonly divided into cooking and beer types based on phenotypic characteristics (Batte et al. 2019; Kitavi et al. 2016; Němečková et al. 2018). The EAHB germplasm that is used as a basis for global EAHB breeding and crop improvement efforts is stored in both in vitro collections (International Transit Center Musa Collection managed by Bioversity International and hosted by the Katholieke Universiteit Leuven) and in field genebanks in Uganda-Mbarara and Tanzania-Sedussu (Kitavi et al. 2016).

East Africa has traditionally been considered as a secondary centre for diversity for East African Highland bananas, based on the presence of multiple phenotypically distinct EAHB cultivars in the region. However, we have previously demonstrated that all EAHB cultivars are genetically uniform at the genomic DNA level, having arisen from a single ancestral clone introduced to Africa, that subsequently underwent population expansion by vegetative propagation by farmers (Kitavi et al. 2016). This raises the question of the underlying basis for the phenotypic diversity observed in vegetatively propagated EAHB cultivars, which has likely arisen due to selection by smallholder farmers for different attributes over multiple generations and geographies. As there is no evidence for seed-based propagation of EAHBs by farmers that would introduce meiotic recombination events, sources of useful and adaptive phenotypic variation for vegetatively propagated EAHBs could consist of rare genetic mutations, genotype-by-environment $(\mathrm{G} \times \mathrm{E})$ effects, epigenotype-by-environment (epi-G $\times E$ ) effects and/or epimutations (epialleles) arising in the somatic lineages that vegetatively propagated EAHB cultivars represent (Kaeppler et al. 2000; Spillane and McKeown 2014).

Transgenerational epigenetic inheritance can occur for both meiotic (e.g. seeds arising from sexual recombination) and mitotic (e.g. vegetative propagation of somatic propagules) transmissions of epialleles (Grossniklaus et al. 2013; McKeown and Spillane 2014; Paszkowski and Grossniklaus 2011; Spillane and McKeown 2014). In plants, examples of epialleles that have likely been inherited over multiple generations (Quadrana and Colot 2016) include the Lcyc epiallele in Linaria vulgaris (Cubas et al. 1999). Environmental stress signals encountered in earlier generations of apomictic lineages of dandelion or inbreeding rice lines have been shown to be associated with heritable changes in epigenetic regulation of small RNAs and DNA methylation (Morgado et al. 2017; Zheng et al. 2017). In addition, epigenetic recombinant inbred lines (epiRILs) of Arabidopsis thaliana have revealed a major contribution of epigenetic variation to phenotypic variation in epiRIL lines that are genetically identical (Cortijo et al. 2014; Kooke et al. 2015; Zhang et al. 2018).

While there are a multiplicity of epigenetic marks at the DNA and chromatin (histone) levels, DNA methylation is a key epigenetic mark which can be mitotically or meiotically transmitted between cells, and between generations (Wendte and Schmitz 2018). DNA methylation, where a methyl group is added to certain cytosine bases, has been the most intensely studied of epigenetic marks and occurs in plants in both symmetric $(\mathrm{CG}, \mathrm{CHG})$ and asymmetric $(\mathrm{CHH})$ contexts $(\mathrm{H}=\mathrm{A}, \mathrm{C}$, or $\mathrm{T})$. Stable patterns of DNA methylation levels between successive generations can arise from the DNA methylation state of the parental cells being faithfully transmitted to the offspring either sexually via meiosis or asexually, as happens during vegetative propagation or apomeiosis (Eichten et al. 2011). Methylated cytosines in CG and CHG contexts allow for transmission between cells and generations of the methylation patterns based on the parental strand information (Lunerova-Bedrichova et al. 2008; Saze et al. 2003). For vegetatively propagated crops, such as EAHBs, DNA methylation-based epialleles arising in somatic cells and tissues can be transmitted to subsequent generations through vegetative propagation that maintains a somatic lineage based on mitotic cell divisions.

To determine whether the genetically uniform, yet phenotypically diverse, genepool of EAHB harbours epigenetic diversity at the DNA methylation level, we profiled cytosine methylation patterns at CCGG sites and characterized methylation patterns across 90 genetically near-identical triploid East African Highlands Banana (EAHB) cultivars, which are phenotypically classified into five morphological clusters. In addition, we investigated whether the heritability of DNA methylation patterns differs depending on whether the DNA methylation status transmission is via meiosis (i.e. sexual reproduction) versus mitosis (i.e. by vegetative propagation). Our findings provide a basis for greater consideration of epigenetic diversity in germplasm conservation, particularly of clonally propagated crops and for incorporation of 
epigenetic markers in breeding programmes of clonally propagated crops.

\section{Materials and methods}

\section{Plant materials}

Three sets of EAHB plant materials were used for this study. Set 1 consisted of ninety genetically near-identical but phenotypically distinct triploid EAHB cultivars (Kitavi et al. 2016) with six outgroup cultivars (Supplementary Table 1): three Plantains (AAB genome), two dessert bananas (AAA genome) and one unknown genome, where $\mathrm{A}$ indicates a set of chromosomes whose ancestry derives from Musa acuminate, while B is indicative of Musa balbisiana ancestry. Set 2 consisted of crossing materials used to assess the inheritance of DNA methylation patterns via meiosis: three triploid EAHB cultivars (Nakawere, Entukura and Enzirabrahima, used as female parental lines for meiotic crosses), a diploid wild accession (Calcutta4, used as the male parent for meiotic crosses), four tetraploid $F_{1}$ hybrids $(201 \mathrm{~K}-1,1438 \mathrm{~K}-1$, $660 \mathrm{~K}-1$ and $917 \mathrm{~K}-1)$ and 52 secondary triploids $\left(F_{2}\right.$ 's) generated from subsequent crossing of the $F_{1} \mathrm{~s}$ with different improved males (C.V rose, SH-3217, Kokopo, Long Tavoy, Malaccensis, SH-3362, SH-3142, 5610s-1 and 9128-3, Supplementary Table 2). Set 3 consisted of nine families of vegetative clones (mother plant and first cycle offspring) (Supplementary Fig. 1) which were used to investigate mitotic transmission of DNA methylation patterns (via vegetative propagation).

The plant materials used in this study were sampled from field genebanks at two different geographical locations, namely (1) 49 EAHB accessions sampled from the east and central African banana regional germplasm collection at Mbarara, Uganda (Hamilton et al. 2016), which stands at an altitude of $1410 \mathrm{~m}$ above sea level, longitude $30^{\circ} 36^{\prime} 8.34^{\prime \prime} \mathrm{E}$ and latitude $0^{\circ} 35^{\prime} 57.29^{\prime \prime} \mathrm{S}$. The Mbarara field genebank contains a total of 182 EAHB accessions (planted in the year 2000), predominantly landraces from Uganda, most of which are varieties that have distinct phenotypes. The remaining 41 EAHB accessions were sampled from (2) the field genebank at the Kenya Agricultural Research and Livestock organization (KALRO) in Kisii which has an altitude of $1818 \mathrm{~m}$ above sea level, latitude: $0^{\circ} 40^{\prime} 26 \mathrm{~S}$ and longitude $34^{\circ} 46^{\prime} 20$. This field genebank was established in 2003 and predominantly comprises landraces from Kenya, with some from Uganda. Only varieties with clearly distinct phenotypes were sampled. Taken together, the 90 EAHB accessions sampled from (1) and (2) represented circa 50\% of the total global EAHB germplasm collection. In the field germplasm collection, each accession is represented by four plants, established from suckers, planted in a single row and with a spacing of $3 \times 3 \mathrm{~m}$ within and between rows. $3-4-\mathrm{cm}$ samples of the cigar leaves of the banana at the same developmental stage were collected from the tip of each fieldgrown plant (Supplementary Fig. 2), and DNA was extracted using a modified CTAB protocol of Dellaporta et al. (1983) and Mace et al. (2003).

\section{Methylation-sensitive amplification polymorphism (MSAP)}

Cytosine methylation of DNA was analysed in EAHB cigar leaf samples using the Keyte et al. (2006) methylation-sensitive amplification polymorphism (MSAP) protocol, with some modifications. For each sample, $250 \mu \mathrm{l}$ of genomic DNA was digested using either the EcoRI/HpaII or $E c o R \mathrm{I} / M s p \mathrm{I}$ restriction enzyme combinations. Ligated DNA fragments were used as templates for pre-amplification with E00 and H/M00 primers (Supplementary Table 3) and the products diluted tenfold for selective amplification with six pairs of three nucleotide selective EcoR1/HpaII primer combinations (Supplementary Table 3). The selective primers were labelled at the $5^{\prime}$ end with either NED ${ }^{\mathrm{TM}}$ (yellow) or 6-FAM ${ }^{\mathrm{TM}}$ (blue) (https://www.appliedbiosystems.com), enabling post-PCR mixing of the products to make a cocktail containing $1.5 \mu \mathrm{l} \mathrm{NED}$ and $1.0 \mu \mathrm{l}$ 6-FAM. GeneScan 500 LIZ internal size standard $(0.012 \mu \mathrm{l})$, formamide $(9 \mu \mathrm{l})$ and $1 \mu \mathrm{l}$ of PCR product cocktail were run and fragments read with a ABI PRISM 3730 XL Genetic Analyser (https://www. appliedbiosystems.com).

\section{MSAP fragment scoring and data analysis}

To ensure consistency between electrophoresis runs, a control sample was included in every run and its fragment profile compared with the other samples in the same run. The advanced peak detection algorithm was used, with light smoothing turned on and all other settings left at default. Holland et al. (2008) bin widths of 0.5 produced topologies with the best resolution; hence, this bin width was used for the final analyses. Only unambiguous, intense bands from 150 to $500 \mathrm{bp}$ were scored (Caballero and Quesada 2010; Liu et al. 2012). The quality of each msAFLP fingerprint and bin was manually checked following Whitlock et al. (2008) and Markert et al. (2010) with slight modifications. We only considered fragments with relative florescence units greater than 100 to reduce background noise. Methylationsensitive fragments were scored for each DNA sample from EcoRI/MspI and EcoRI/HpaII-digested DNA using Genemapper v4.1 (Applied Biosystems). Following the protocol of Fulneček and Kovařík (2014), four MH fragment pattern variants ',,,++--+--+ ', referring to the presence $(+)$ or absence (-) of a fragment, were called. Interpretation of methylation-sensitive amplified polymorphism (MSAP) 
fragment profiles was based on Fulneček and Kovařík (2014).

\section{Status of DNA methylation among triploid EAHB cultivars}

To assess the extent of cytosine methylation of the EAHB cultivars, MSAP scorings (from differential digestion) were used to infer global methylation level (i.e. the proportion of total cytosines that are methylated irrespective of their specific sequence context). Total DNA methylation levels were calculated with the MsapR package v1.1.9 (PérezFigueroa 2013). Individual fragments (loci) were classified based on their restriction pattern as methylation-susceptible loci (MSL) or non-methylated loci (NML): $+/-$ as $\mathrm{mCm}$ CGG, +/- as CmCGG, $-/+$ as indeterminate methylation of an internal CCGG site on an EcoRI and MspI/HpaII digested band (either mCCGG or CmCGG), or as non-methylated loci $(+/+)$. Significance was determined using multi-sample nonparametric Kruskal-Wallis tests with one-way ANOVA and Dunn's multiple comparison test. The diversity of the MSL and NML was assessed by calculating Shannon's index of phenotypic diversity, $S$, derived from the Shannon-Weaver index (Shannon 1948) as $S=-\sum_{i-1}^{n} p_{i} \log 2 p_{i}$, where $P_{i}$ is the frequency of the band presence at the $i$ th marker within the population) using msap v1.1.9. Overall epigenetic population differentiation, $\beta S T$ (based on MSL), was calculated in msap v1.1.8.

\section{Within and between morphological-group analysis}

The level and diversity of methylation states in the morphological clusters were calculated in R software version 3.6.1. To investigate the patterns of epigenetic variation within and between the EAHB phenotypic groupings, PCoAs were constructed from the MSL and NML cultivar profiles using the msap v1.1.8 package in R (supported by Mantel's test with 1000 permutations) and visually compared. Transformation of the multistate raw data matrix from the EcoRI/HpaII and EcoRI/MspI profiles into a binary data matrix allowed statistical analyses and computation of descriptive indices such as epigenetic diversity between cultivars. AMOVA analysis was applied to the pairwise distance matrix to partition the sources of the observed variation by component parts.

Multivariate analysis was used to explore epigenetic structure between morphological groups. Principal coordinate analyses (PCoA) were performed on inter-profile covariance matrices based on MSL and NML binary profiles (Liu et al. 2012). PCoA profiles were grouped into populations maximizing the between-group variance using between Eigen analyses (BPCA) (Lira-Medeiros et al. 2010; Liu et al. 2012; Parisod and Christin 2008). Statistical significance was assessed by the Romesburg randomization test $\left(10^{4}\right.$ permutations). Multivariate analyses were performed to obtain a PCoA using dudi.pco and s.class with the R package ade4 v1.7.13 (Thioulouse et al. 1997).

\section{Epigenetic population structure and relationships}

The inherent epigenetic structure of EAHB population was investigated using the Pritchard et al. (2000) method that implements a model-based clustering method in the program STRUCTURE v2.3.4. Characterized by a set of allele frequencies at each locus, the EAHB cultivars were assigned to populations $(K)$, identified as migrants or admixed using MSAP multilocus genotype data independent of prior population information (Pritchard et al. 2000). The number of possible Ks (1-10) was assessed in three replicates assuming the admixture model with correlated allele frequencies and 20 independent runs with 100,000 Markov Chain Monte Carlo (MCMC) iterations and 100,000 burn-in. Lambda was set at the program default of 1.0 for exploratory analyses without a priori information about individual origin. The most likely value of $K$ was derived using the second-order rate of change $L^{\prime \prime}(K)$ (Evanno et al. 2005; He et al. 2011; Lerceteau-Kohler et al. 2013) using the online tool Structure Harvester (https ://taylor0.biology.ucla.edu/struct_harvest).

\section{Heritability of methylated loci in meiotic $F_{1}$ hybrids versus mitotic progeny of East African Highland bananas}

The level and diversity of methylation states in parents versus their offspring were calculated in R. Differentiation of the non-methylated and methylation-susceptible loci of the meiotic progeny versus the mitotic progeny was calculated based on the $\varphi$ st values of the loci. Methylation patterns present in both the parents and their corresponding offspring were regarded as inherited. Methylated-loci bands that were present in offspring and not in their parents were regarded as new methylation marks. Loss of methylation was scored where bands were present in the parents but missing in their respective offspring. Significant differences in methylation levels between parent(s) and subsequent generations were determined by oneway ANOVA with Tukey correction, as well as with the Kruskal-Wallis test and Dunn test of multiple comparison to determine differences between the methylation states across subdivisions within the data. 


\section{Results}

\section{Global DNA methylation variation across the EAHB genepool}

The levels and diversity of methylation patterns in 90 East African Highland Banana (EAHB) cultivars and outgroups were determined using MSAP with the methylation-sensitive isoschizomeric restriction enzymes HpaII and MspI. The $(+,+)$ pattern (a fragment visualized in both the Msp and Hpa profiles) was attributed to digestion by both enzymes at a non-methylated CCGG site. The $(-,-)$ pattern indicated inhibition of digestion with both enzymes at a fully methylated $\mathrm{mCmCGG}$ site. The $(+,-)$ pattern which represents a fragment of a defined size visualized in the MspI but not in the HpaII profile corresponds to digestion with MspI but not HpaII and indicates the presence of a CmCGG site (CG methylation). The $(-,+)$ pattern observed in HpaII but not in MspI is difficult to interpret unambiguously in plant genomes (where methylation occurs in both the CCG and CG motifs) and is indicative of a CCGG site within the band: that is, it corresponds to either a CmCGG site or a mCCGG site (Fulneček and Kovařík 2014). MSAP data were combined into two datasets: Dataset 1 (from EAHB sample set 1) included 724 fragments and was used for the analysis of DNA methylation polymorphism and epigenetic structure of the EAHB population. Dataset 2 (from EAHB sample sets 2 and 3) included 1868 bands and was used to assess the transgenerational inheritance of DNA methylation patterns via meiosis (parental line, sexual crosses $F_{1}$ s crosses (tetraploids) and $F_{2} \mathrm{~s}$ ) and mitosis (vegetative clones and first cycle offspring).

Within the EAHB populations, a total of 724 bands were identified from MSAP and were used to perform principal coordinate analyses (PCoA) to explore epigenetic structure between morphological groups. Of these bands, 622 corresponded to potentially methylation-sensitive loci (i.e. MSL) and 102 bands to non-methylated loci (i.e. NML). The MSL sites were polymorphic (52\% of the total MSL; Shannon's Diversity Index $(I)=0.3015$; SD: 0.2289) and varieties were spread across the PCoA (Fig. 1a) compared to the non-methylated loci (63\% polymorphic bands, Shannon's Diversity Index $(I)=0.1547$; SD: 0.0784 (Fig. 1b), reflecting the status of variation in the two profiles. Differences in variation in the MSL and NML were significant (Wilcoxon rank sum test with continuity correction; $W=13,501 ; P<0.0001)$. Across all MSL, instances of non-methylation occurred at $21.39 \%$ of loci, mCmCGG methylation at $46.3 \%$, CmCGG methylation at $14 \%$ and indeterminate methylation at $18.31 \%$ (Fig. 2).

\section{MSAP DNA methylation levels and patterns do not epigenetically differentiate the five major morphological groups of EAHBs}

To determine whether epigenetic marks could distinguish between the five major recognized EAHB morphological groups, we compared their levels and patterns of DNA methylation (Fig. 3). The mean 5'-CCGG-methylation level among the morphological groups was $76.5 \%$ (of total loci scored) within a range of $76.2 \%$ (Musakala, the oldest cloneset) to $76.6 \%$ (Nakitembe). Statistical significance was observed in the proportions of each methylation state versus the other three states (Dunn`s Multiple comparison test, $P<0.0001$ for all tests). The level of polymorphisms of the methylated loci did not differ significantly among the five morphological groups (Kruskal-Wallis $x^{2}=2.096$, $P=0.7181 ; x^{2}=6.349, P=0.1745 ; x^{2}=3.655, P=0.4548$ and $x^{2}=1.587, P=0.8112$ for CCGG sites, indeterminant internal sites, $\mathrm{CmCGG}$ sites and $\mathrm{mCmCGG}$ sites, respectively). AMOVA shows $>98 \%$ of the morphological groups' genetic variation occurs within populations rather than between them. We conclude that patterns of total DNA methylation and DNA methylation polymorphisms show no meaningful epigenetic differences between morphologically distinct groups of EAHB cultivars.

\section{Geographic epigenetic differentiation of genetically identical EAHB populations}

As DNA methylation patterns only vary slightly between morphological groups, we considered what other factors might explain the epigenetic differentiation in EAHB. We considered the possibility of underlying epigenetic population structure not relating to morphology within the sampled bananas. Hence, we analysed the populations with Structure (Pritchard et al. 2010), assigning each cultivar to (epi)-populations $(K)$, identified as migrants or admixed using MSAP multilocus genotype data independent of prior population information (Pritchard et al. 2000). The optimal number of Ks (1-10) was determined to be $K=5$ (Fig. 4a) using both methylation-susceptible loci (MSL) and non-methylated loci (NML) datasets, as described in Methods. This resolved two groups indicative of the Dessert bananas and the Plantains, a group present in all groups except the Plantains (particularly in sample 61), and two groups that clustered according to whether the samples were taken from the Kenyan or Ugandan sites (Fig. 4b). We conclude that genetically near-identical EAHB cultivars are epigenetically distinguished on the basis of DNA methylation patterns that are associated with the two geographic regions (Uganda vs Kenya) from which they were sampled. To reflect this, outgroup 1, an EAHB from the Kenyan site of Unknown morphological grouping, 
Fig. 1 Principal coordinates analyses (PCoAs) illustrating variation between the 90 EAHB cultivars and six outgroup varieties (S/No. 1-96, Supplementary Table 1) based on a the methylated loci (MSL) and b non-methylated loci (NML) (a)

(a)

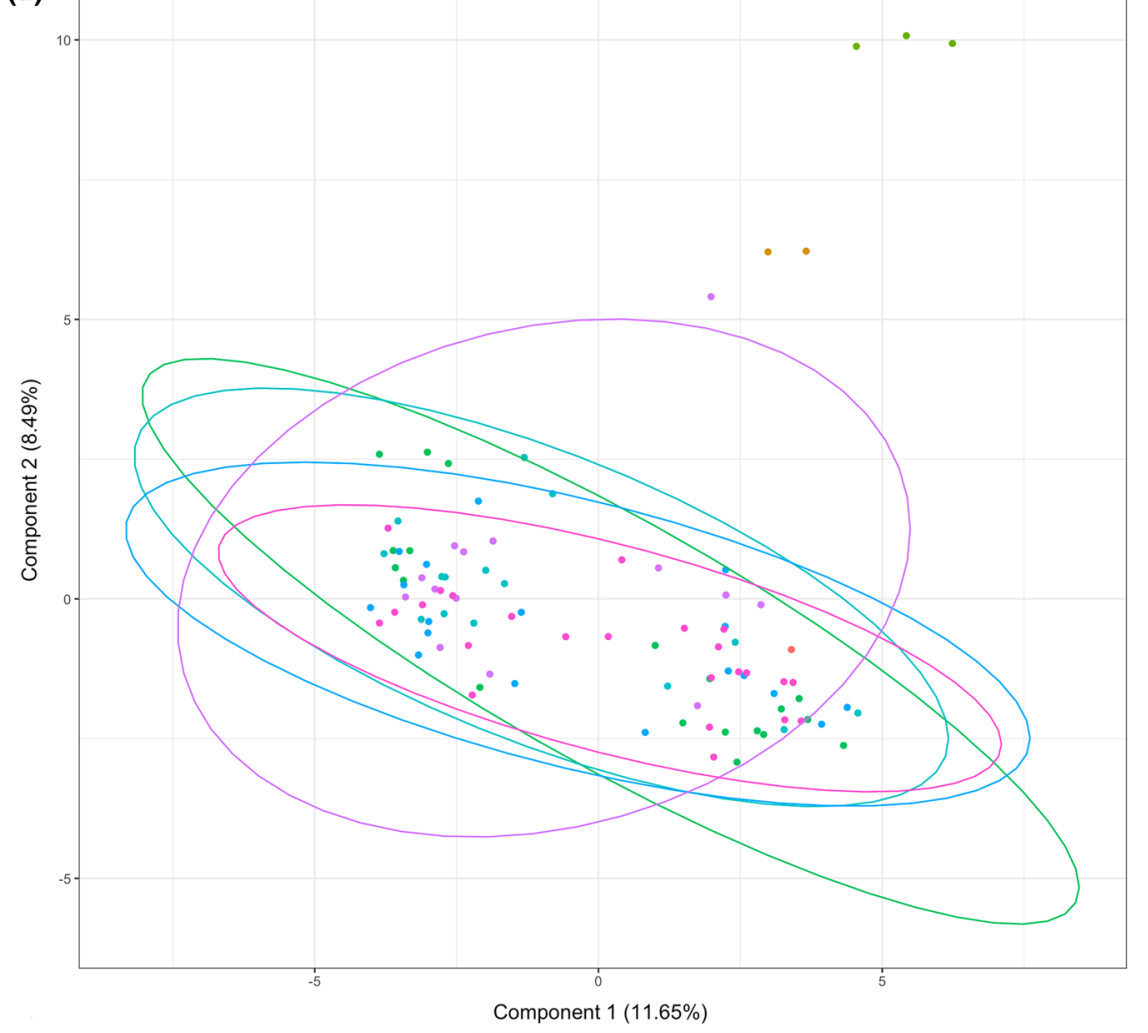

(b)

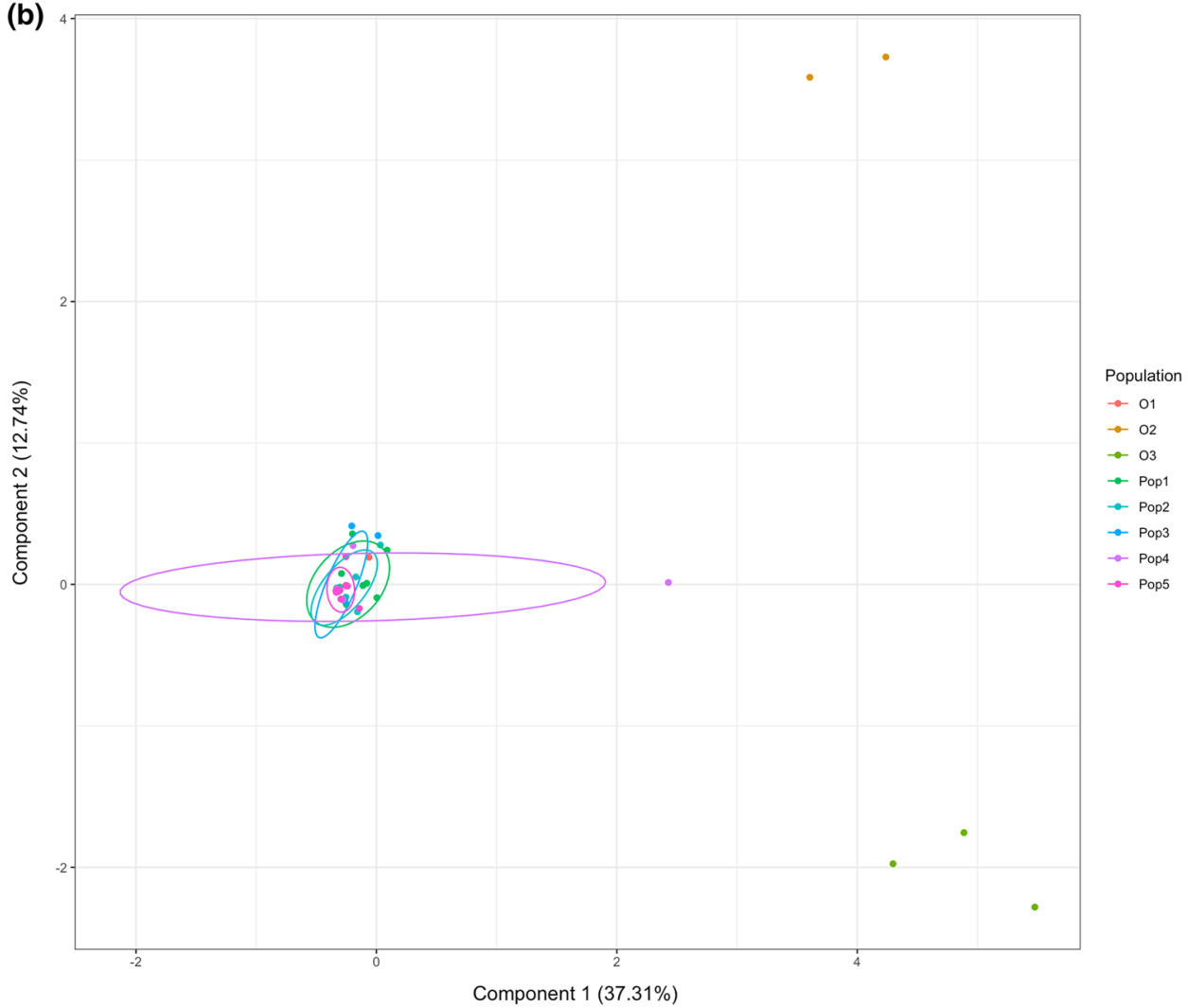


was reclassified as part of the 90 cultivars, which henceforth are distinguished on the basis of sampling origin.

To further investigate the DNA methylation patterns in the five EAHB morphological groups, we generated a covariance matrix of their respective methylation profiles to perform between-group Eigen analysis (BPCA), with groups assigned based on the origin of the sample (Fig. 5). The first two axes of the BPCA for the MSL accounted for $82.9 \%$ of the total inertia between groups (Fig. 5a) while the first two axes of the BPCA for the NML summarized $97.2 \%$ of the inertia. In terms of the inertia of the PCoAs i.e. the variance both between and within groups; the MSL BPCA accounted for $21.6 \%$ of total inertia in the MSL, while the NML BPCA accounted for $49.2 \%$. The MSL displayed separation of the two sampling sites along the first principal component and separation of the outgroups from the EAHBs along the second, while the NML only distinguished the outgroups from the EAHBs along its first two principal components (Fig. 5b). Comparisons of the methylated and non-methylated profiles between the sampling sites showed epigenetic differentiation (as measured by $\varphi s t$ values), albeit with greater distance between the EAHB sites and the outgroups than within the EAHBs, while the NML showed very short distances between the EAHBs and considerable distances between the EAHBs and the outgroups (as well as between the two outgroups) (Table 1b). In contrast, the $\varphi$ st values for the morphological groups show little distance between themselves in either the MSL or NML, and very little significance in the comparisons measuring this distance. Distances between the morphological groups and the outgroups show significantly longer distances between the NML of the morphological groups and outgroups than the MSL. The unknown outgroup shows shorter and insignificant distance from the morphological groups, showing evidence it belongs among these groups. Dessert bananas and plantains are of roughly equivalent distance in the NML, but plantains show greater distance in the MSL profiles.

\section{Epigenetically divergent genetic clones and selection of East African Highland banana cultivars}

Heritable epigenetic modifications can have morphological, physiological and ecological consequences, including across generations and geographies. Our previous studies have shown that EAHBs are genetically uniform, arising from a

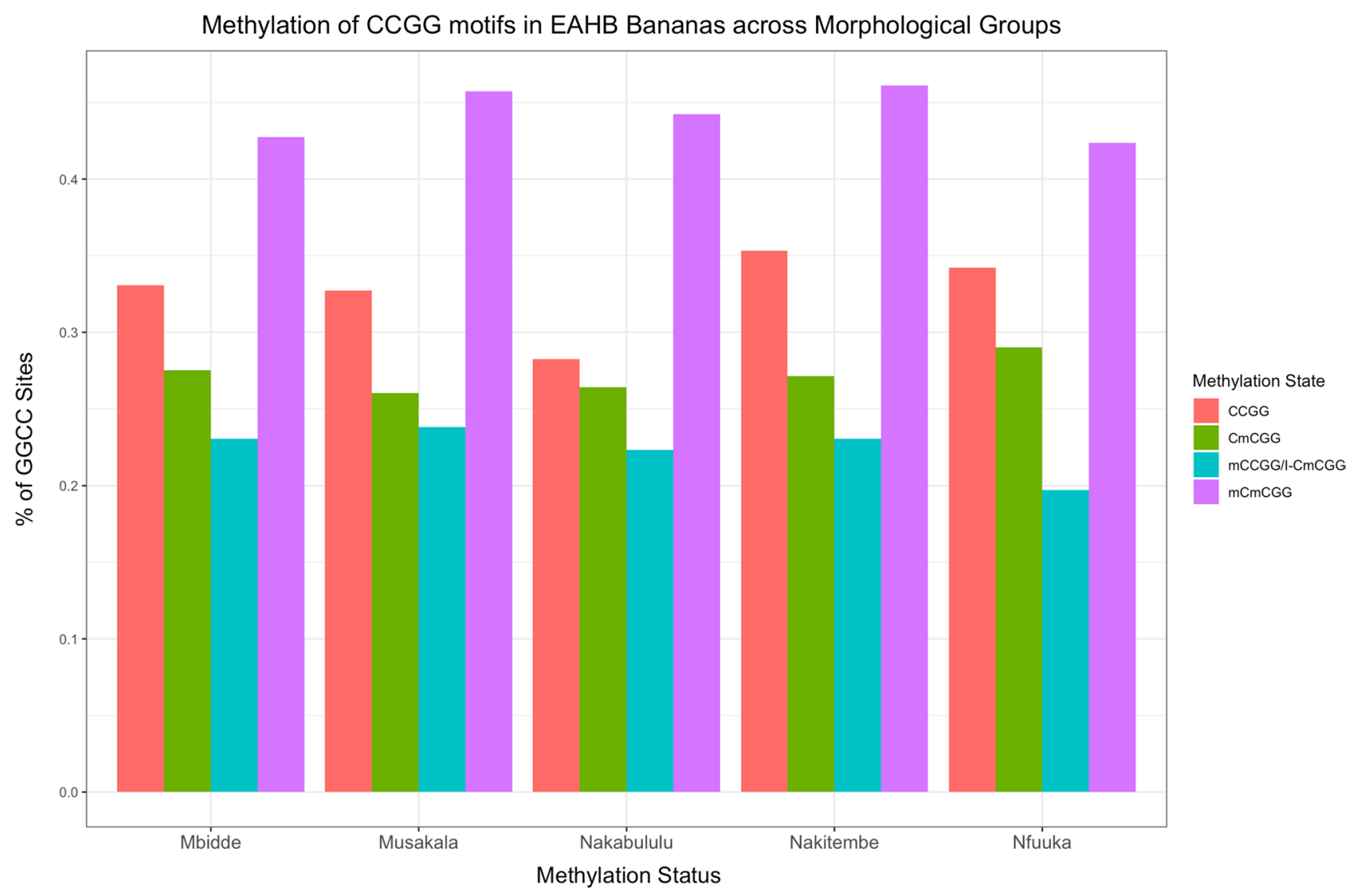

Fig. 2 Proportion of genome-wide cytosine methylation in 724 MsAFLP loci of 90 EAHB cultivars. Differences in the number of the four types of fragments scored in the 90 cultivars were significant (Kruskal-Wallis test $P<0.0001$, *** and Dunn's Multiple comparison test) 
single ancestral clone that has since been vegetatively propagated and gave rise to the morphology-based EAHB germplasm collections that exist today (Kitavi et al. 2016). The morphological characteristics that differentiate EAHB cultivars must likely arise as a result of somaclonal mutations, mitotically inherited epigenetic mutations and/or genotypeby-environment (or epigenotype-by-environment) interactions. The epigenetic variation we have detected across the different EAHB cultivars (which are near isogenic) raises the possibility that heritable epigenetic mutations could be the source of phenotypic variation for new EAHB cultivars selected by farmers.

To investigate this possibility, we constructed a neighbour joining (NJ) tree representing phylo-epigenetic differences in clones grown in different fields, represented in different colours in Fig. 6 (clones 7 and 24 in blue, 45 and 44 in light green, 80 and 81 in pink; cultivar names in Supplementary Table 1), variants of the same clone growing in the same field (61, 62 and 65, all yellow) and lineage clones (mother plant 74, two sister clones, 75 and 76 all red). Clones 75 and 76 are derived from the same mother so should genetically be considered as clones, but differ in the phenotype of their rachis, prompting farmers to consider them as two different cultivars. Intriguingly, the $\mathrm{NJ}$ tree indicates the existence of epigenetic differentiation among groups of genetically identical EAHB clones with phenotypic differences. Consider, for example, the distance between 75 and 76: the former remains tightly clustered with 74 , its mother clone, while 76 diverges. Similarly, 80 and 81 are even further apart despite being sister clones and therefore genetically identical. We conclude that environmental factors (including farmer selection) experienced by the clones during their cultivation generate differences in their DNA methylation, including in groups of clones that display agriculturally relevant phenotypic differences.

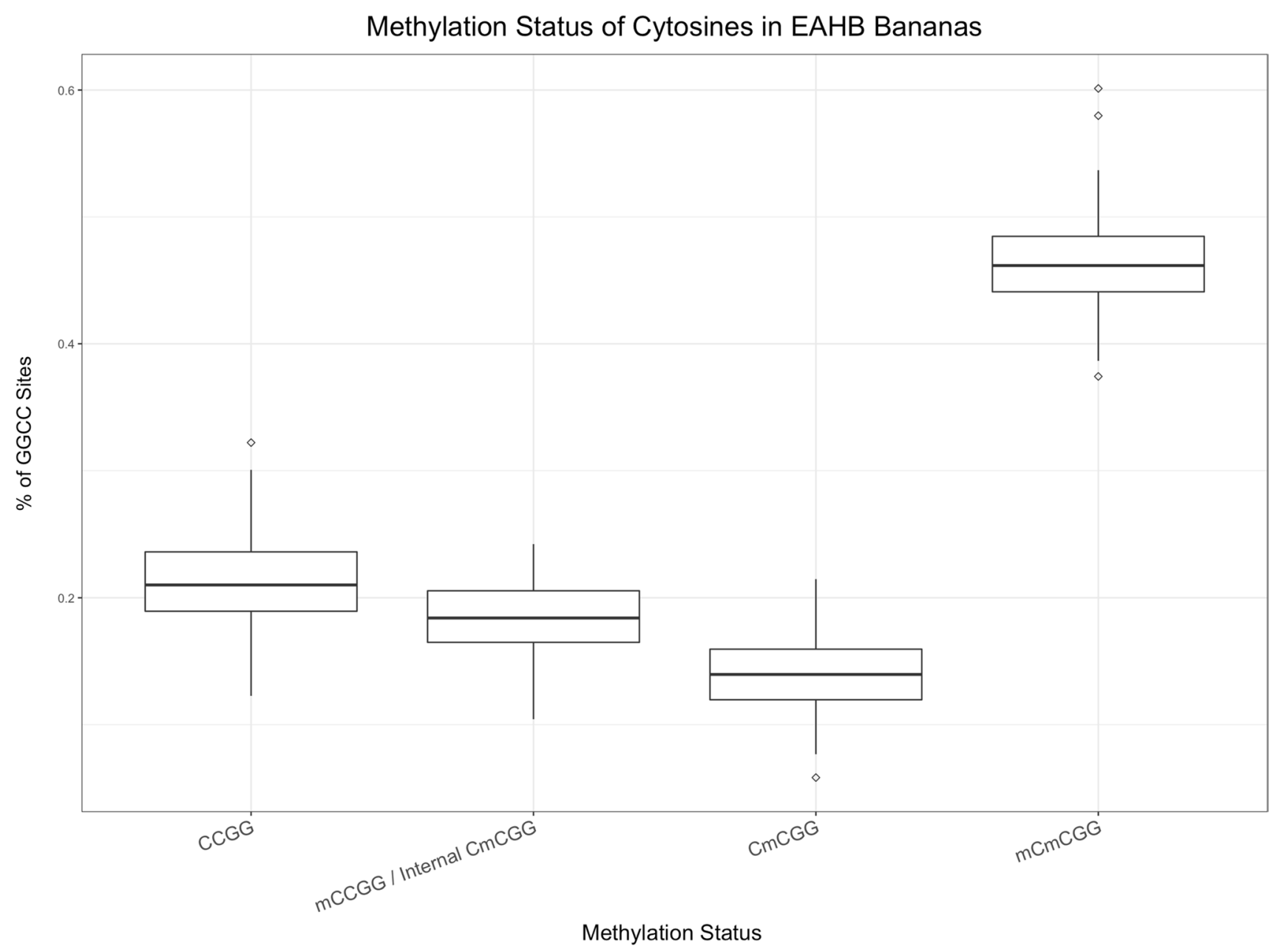

Fig. 3 Relative proportions of CCGG methylation state (mCmCGG, CmCGG, CCGG and mCCGG/i-CmCGG) in 724 MSAP loci of cultivars in the five EAHB morphological groups 


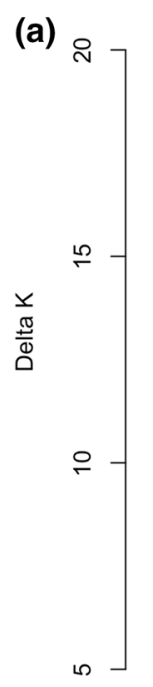

(b)

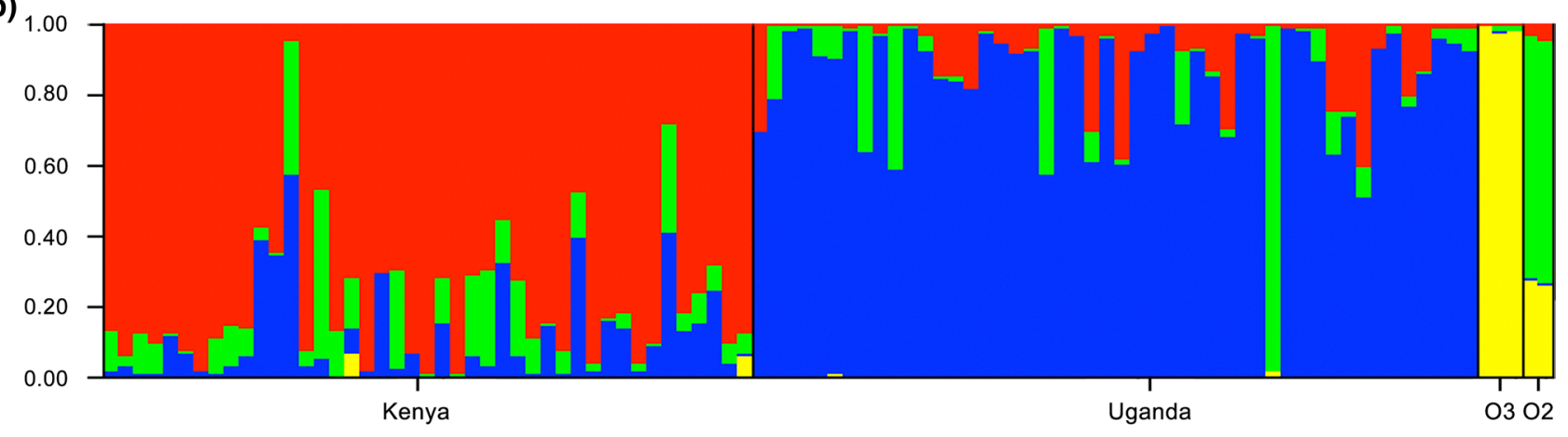

Fig. 4 Epigenetic population structure and PCA of the EAHB. a Evanno test for determining the number of populations within the MSAFLP loci, b population structure was evaluated using STRUCTURE v2.3.3

\section{Meiotic and mitotic transgenerational inheritance of cytosine methylation patterns in EAHB}

DNA methylation can affect chromatin structure and transcriptional regulation and thereby impact on biochemical and/or morphological phenotypes. However, for DNA methylation-associated phenotypes to persist it requires that the responsible DNA methylation states (epialleles) are heritable, either meiotically (e.g. via seeds) or mitotically (e.g. via vegetative propagation). To determine whether the differences in DNA methylation observed between EAHB clones are heritable and thus able to contribute to adaptation of cultivars, we performed a further MSAP analysis to investigate DNA methylation levels and CCGG patterns in groups of parents and their meiotic (seed) and mitotic (vegetative propagated) progeny. Specifically, we generated sexual (meiotically derived) families by crossing four parental varieties of EAHB with a wild diploid cultivar, Calcutta4, as shown in Fig. 7 a, to generate four sets of $F_{1}$ offspring which were then backcrossed to generate divergent $F_{2}$ offspring; 13 of these were randomly selected for analysis, giving $52 F_{2}$ in total. In addition, asexual (clonal) vegetatively propagated families were assessed from nine groups of clonally propagated parents and between two and four of their progeny. DNA methylation profiles were then analysed in all these meiotic and mitotic families using 10 primer combinations. 

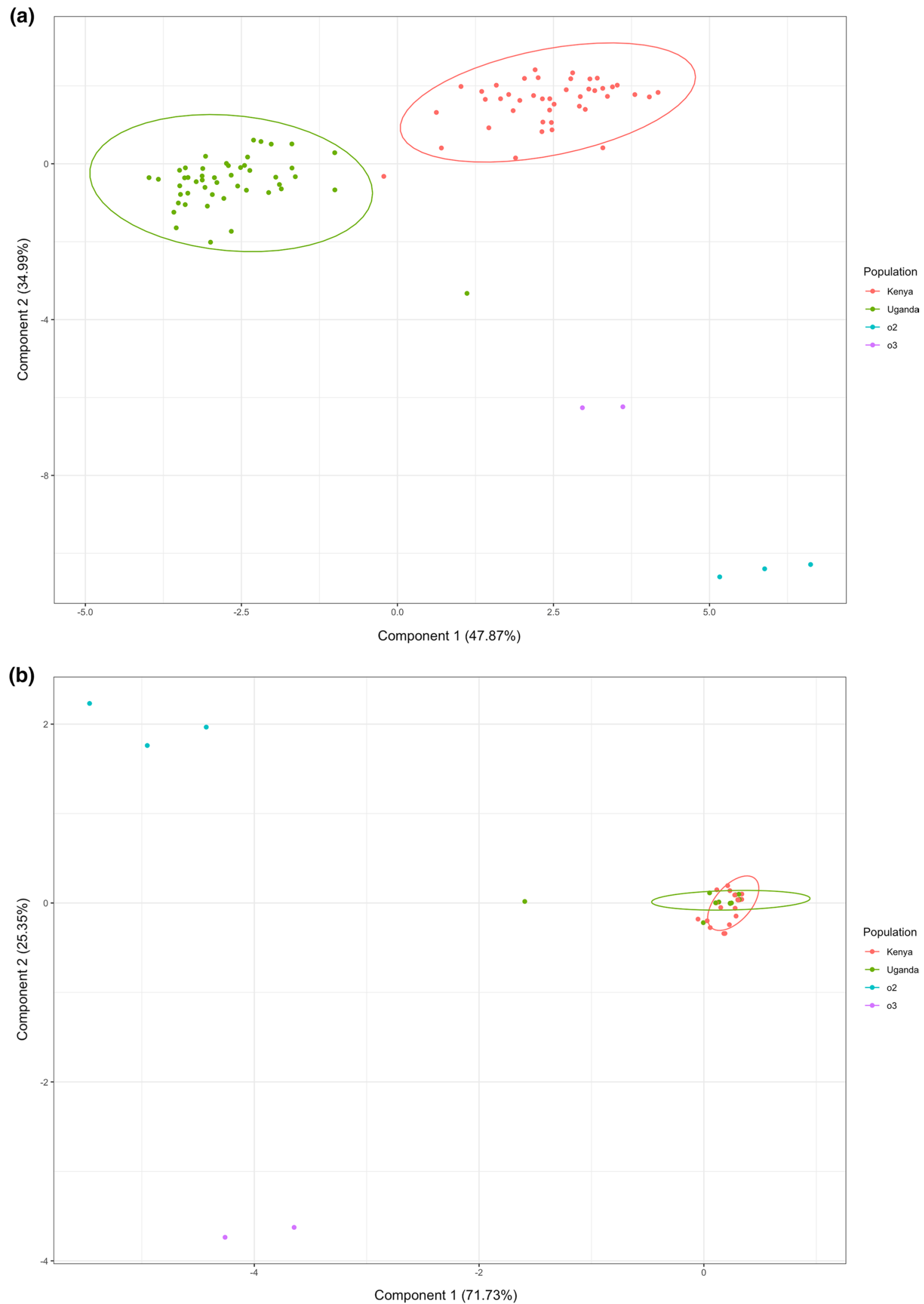

Fig. 5 Between-group Eigen analysis (BPCA) based on the a MSL, b NML of the EAHB sampling sites (Kenya and Uganda) and outgroups (AAA — dessert banana, labelled as 'O3', and AAB — plantain, labelled as 'O2'). Component 1 and Component 2 values show the contribution of the two principal components, summarizing the total variance of each data set 
A total of 1868 loci were analysed of which $98 \%$ were methylated (MSL), with the remainder non-methylated (NML); the error rate per primer combination was 0.05 . As before, the MSL was found to be significantly more diverse than the NML (Shannon's Diversity Index $(I)=0.3345$; SD 0.2057 vs $\mathrm{I}=0.2060 ;$ SD 0.076 ; Wilcoxon rank sum test with continuity correction $\mathrm{W}=36,128 ; P<P=0.00156$ ). When progeny produced by the sexual (seed, meiotic) and asexual (clonal, mitotic) modes of propagation was compared, both were found to be highly polymorphic in both their MSL and NML fractions: $85 \%$ and $74 \%$ for MSL in the sexual and asexual progeny and $100 \%$ and $87 \%$ in the NML. In all cases, these were significantly diverse by Shannon's Diversity Index (Table 2). A mantel test for correlation among the MSL and NML profiles of the two reproductive methods shows no significant correlation in the meiotic populations while small amount of significant correlation is seen in vegetative propagated populations (Table $2 ; r=0.13$ and $P=0.092$ vs $r=0.276$; and $P=0.018$ ), suggesting that meiotic recombination led to segregation of these loci.

The levels of CCGG-methylated sites in the parental lines (EAHB females; triploids and Calcutta 4; diploid), the $F_{1}$ (tetraploids) and $F_{2}$ (triploids) were then compared (Fig. 7a). Using Dunn's test of multiple comparison, no significant variation in methylation levels as determined by MSAP was detected between any of the generations used to generate offspring meiotically within families derived from an $F_{0}$ parent. In addition, no variation was found in the levels of each type of methylation across all families. A lack of significance is also observed with respect to differences in methylation levels of vegetatively propagated offspring and their parents, and this observation holds true both within and between vegetatively propagated families (Fig. 7b). Comparing the generations across the two subpopulations shows no significant difference in the proportions of loci occupying each of the methylation states between the sexual and asexual populations.

\section{Heritability of methylated loci in meiotic offspring versus mitotic offspring of East African Highland bananas}

Methylated states (i.e. CCGG, $\mathrm{CmCGG}$, $\mathrm{mCmCGG}$ and indeterminate methylated sites) present in the parents and their corresponding offspring were regarded as shared and therefore as potentially stably inherited. Methylation occurring in the offspring and not in their parents was regarded as novel. Loss of methylation was considered as methylation present at a locus in the parents that was missing in their respective offspring. Significant differences in abundances of the methylation states were not detected between parent(s) and subsequent generations
Table 1 Pairwise $\varphi$-ST values of MSL and NML comparing methylation-sensitive and methylation-insensitive differentiation among (a) the EAHB morphological groups and (b) the sampling site, with outgroups denoted as distinct from the sites

\begin{tabular}{|c|c|c|c|c|c|}
\hline Cloneset A & Cloneset B & MSL & $\mathrm{P}(\mathrm{MSL})$ & NML & $\mathrm{P}(\mathrm{NML})$ \\
\hline \multicolumn{6}{|c|}{$a$} \\
\hline Nakabululu & Nfuuka & 0.002 & 0.343 & 0.004 & 0.352 \\
\hline Musakala & Nakitembe & 0.001 & 0.390 & -0.019 & 0.902 \\
\hline Nakitembe & Nfuuka & 0.023 & 0.061 & 0.016 & 0.196 \\
\hline Mbidde & Nfuuka & 0.017 & 0.079 & 0.046 & $<0.001$ \\
\hline Musakala & Nfuuka & 0.026 & 0.048 & 0.013 & 0.204 \\
\hline Mbidde & Nakabululu & 0.022 & 0.076 & 0.008 & 0.241 \\
\hline Nakabululu & Nakitembe & 0.017 & 0.120 & 0.003 & 0.370 \\
\hline Musakala & Nakabululu & 0.023 & 0.091 & 0.001 & 0.430 \\
\hline Mbidde & Musakala & 0.035 & 0.049 & 0.011 & 0.200 \\
\hline Mbidde & Nakitembe & 0.034 & 0.033 & 0.017 & 0.149 \\
\hline $\begin{array}{l}\text { O1 } \\
\text { (Unknown) }\end{array}$ & O2 (Dessert) & 0.662 & 0.327 & 0.539 & 0.338 \\
\hline $\begin{array}{l}\text { O1 } \\
\text { (Unknown) }\end{array}$ & O3 (Plantain) & 0.611 & 0.262 & 0.594 & 0.247 \\
\hline $\begin{array}{l}\text { O1 } \\
\text { (Unknown) }\end{array}$ & Nfuuka & 0.050 & 0.278 & 0.260 & 0.151 \\
\hline $\begin{array}{l}\text { O1 } \\
\text { (Unknown) }\end{array}$ & Nakitembe & 0.089 & 0.196 & -0.077 & 0.199 \\
\hline $\begin{array}{l}\text { O1 } \\
\text { (Unknown) }\end{array}$ & Nakabululu & 0.087 & 0.210 & 0.342 & 0.215 \\
\hline $\begin{array}{l}\text { O1 } \\
\text { (Unknown) }\end{array}$ & Mbidde & 0.031 & 0.403 & 0.235 & 0.346 \\
\hline $\begin{array}{l}\text { O1 } \\
\text { (Unknown) }\end{array}$ & Musakala & 0.122 & 0.371 & 0.184 & 0.251 \\
\hline O2 (Dessert) & O3 (Plantain) & 0.656 & 0.102 & 0.626 & 0.102 \\
\hline O3 (Plantain) & Nfuuka & 0.560 & $<0.001$ & 0.878 & $<0.001$ \\
\hline O3 (Plantain) & Nakitembe & 0.522 & 0.002 & 0.761 & 0.001 \\
\hline O3 (Plantain) & Nakabululu & 0.561 & $<0.001$ & 0.873 & $<0.001$ \\
\hline O3 (Plantain) & Mbidde & 0.546 & $<0.001$ & 0.854 & $<0.001$ \\
\hline O3 (Plantain) & Musakala & 0.611 & 0.001 & 0.841 & 0.002 \\
\hline O2 (Dessert) & Nfuuka & 0.403 & 0.004 & 0.887 & 0.003 \\
\hline O2 (Dessert) & Nakitembe & 0.353 & 0.008 & 0.765 & 0.009 \\
\hline O2 (Dessert) & Nakabululu & 0.398 & 0.006 & 0.885 & 0.005 \\
\hline O2 (Dessert) & Mbidde & 0.382 & 0.005 & 0.864 & 0.005 \\
\hline O2 (Dessert) & Musakala & 0.376 & 0.008 & 0.852 & 0.008 \\
\hline \multicolumn{6}{|l|}{$b$} \\
\hline Kenya & O2 (Dessert) & 0.555 & $<0.001$ & 0.856 & $<0.001$ \\
\hline O3 (Plantain) & Kenya & 0.402 & $<0.001$ & 0.858 & 0.001 \\
\hline Kenya & Uganda & 0.195 & $<0.001$ & 0.016 & 0.013 \\
\hline O2 (Dessert) & O3 (Plantain) & 0.656 & 0.102 & 0.626 & 0.102 \\
\hline Uganda & O2 (Dessert) & 0.595 & $<0.001$ & 0.866 & $<0.001$ \\
\hline O3 (Plantain) & Uganda & 0.450 & $<0.001$ & 0.870 & $<0.001$ \\
\hline
\end{tabular}


using one-way ANOVA and Tukey's test. Of note is an inability of this analysis to completely rule out novel epigenome reorganization that coincidentally matches the state of the parent. Efforts were made to account for de novo methylation states in the $F_{2}$ that happened to match the $F_{1}$ father, where analysis shows evidence for biased inheritance of one site type over others in certain contexts. However, none of the sites analysed offer convincing evidence of methylation-sensitive loci that are stably inherited in unique contexts.

In the meiotic families, the probability of methylation patterns being shared between both parents and $F_{1}$ offspring was $34.1 \%$, with loci exclusive to the maternal parent comprising $16.7 \%$ and paternally exclusive loci being shared with $18 \%$ of loci (Fig. 8). Analysis pertaining to inheritance from the $F_{0}$ generation is only available for three of the four families, as no data exist for the methylation profile of the Nakawere $F_{0}$ parent. In contrast, for the vegetatively propagated asexual families, the proportion of methylated loci shared between parents and progeny ranged from 47.7 to $69.9 \%$ across the families, but with no significant difference detected between the vegetatively propagated families (Fig. 9) The overall rate for inheritance in mitotically reproducing families was $56.2 \%$.

Analysis of the DNA methylation patterns of the parents and their offspring revealed patterns that were apparent across the set of loci as a whole but not evident at the individual level. Inherited loci in the $F_{1}$ generation can be attributed to either a single parent, both parents or neither, while the $F_{2}$ generation can be attributed to either having been inherited solely from the $F_{0}$ maternal parent or the $F_{1}$ parents, or shared inheritance from a combination of these individuals. No significant differences were detected in comparisons between the $F_{1}$ progeny and the $F_{0}$ parents (Table 3 ), but differences that become significant in the $F_{2}$ generation are present. Examining inheritance in the $F_{2}$ (Table 4) in terms of family revealed that the mean proportion of loci in the $F_{2}$ generation shared with the $F_{0}$ parents, as determined by presence in the $F_{0}$ and $F_{1}$, was significantly greater in the two Enzirabahima families than in the Entukura family. Consequently, the Entukura had a greater inheritance of novel loci from the $F_{1}$ maternal genome then that of the other two families. Testing for significant difference between methylation states in terms of the attributable sources of inheritance showed that methylated loci are disproportionately inherited at loci where both parents are also methylated at the loci, while inheritance of non-methylated states seems to prevail at loci that either matched to only one parent or were novel within that individual. Analysis was also carried out at the level of individual loci to determine whether a family-specific pattern of inheritance could be observed across multiple generations. For each family, $9-15$ loci in the $F_{2}$ generation were found to be have a significantly greater inheritance of a locus in the $F_{1}$ maternal genome in comparison to every other family. Each of these loci, however, is methylated and is not always inherited from the $F_{0}$ generation. To summarize, a significant difference in the prevalence of $\mathrm{mCmCGG}$ loci over any other loci appearing in both parent and offspring can be detected in the meiotically generated families, but to what degree genuine inheritance as opposed to spurious matching of the most prevalent of potentially freely changing loci is occurring is unclear.

Investigation of the vegetatively propagated individuals in terms of methylation state showed a similar pattern of global methylation state occupation (Fig. 9), as is expected given the lack of significant difference between the mitotically reproducing and meiotically reproducing populations. For each family, no significance in inheritance of any methylation state over any of the others inherited was detected, but across all families a bias towards inheritance of $\mathrm{mCm}$ CGG loci could be discerned through multiple comparisons. Our results indicate that EAHBs can maintain many DNA methylation sites over generations when propagated either sexually or asexually, but maintain more DNA methylation sites when clonally (vegetatively) propagated. In addition, both modes of generation of offspring display losses and gains of methylated DNA sites, indicating that DNA methylation epiallelic diversity is dynamic during both sexual reproduction and asexual reproduction of EAHBs. Outside of the EAHB breeding programme, EAHBs have been vegetatively propagated by farmers for centuries, where the scale of such activities provides significant opportunity for epialleles affecting agronomic phenotypes of EAHBs to arise as geographically isolated, epigenetically distinct, varieties in different environments. Where such 'functional' epialleles are maintained over multiple vegetative generations, they could form a key underpinning component of the phenotypic diversity of EAHBs that is conserved in field genebanks.

\section{Discussion}

The EAHB germplasm that is used as a basis for EAHB breeding and crop improvement efforts is stored in field germplasm collections in Africa and also in in vitro collections at the International Musa Germplasm Transit Centre (ITC), managed by Bioversity International and hosted at the Katholieke Universiteit Leuven (KU Leuven), Belgium. The main EAHB field genebanks are in Uganda (at the east and central African regional collection at Mbarara) and Kenya (at Kenya Agricultural Research Institute, now the Kisii Regional Research Center. We have previously demonstrated that the triploid East African Highland Banana (EAHB) genepool is genetically uniform arising from a single ancestral clone that underwent population expansion by vegetative propagation (Kitavi et al. 2016). Despite the 


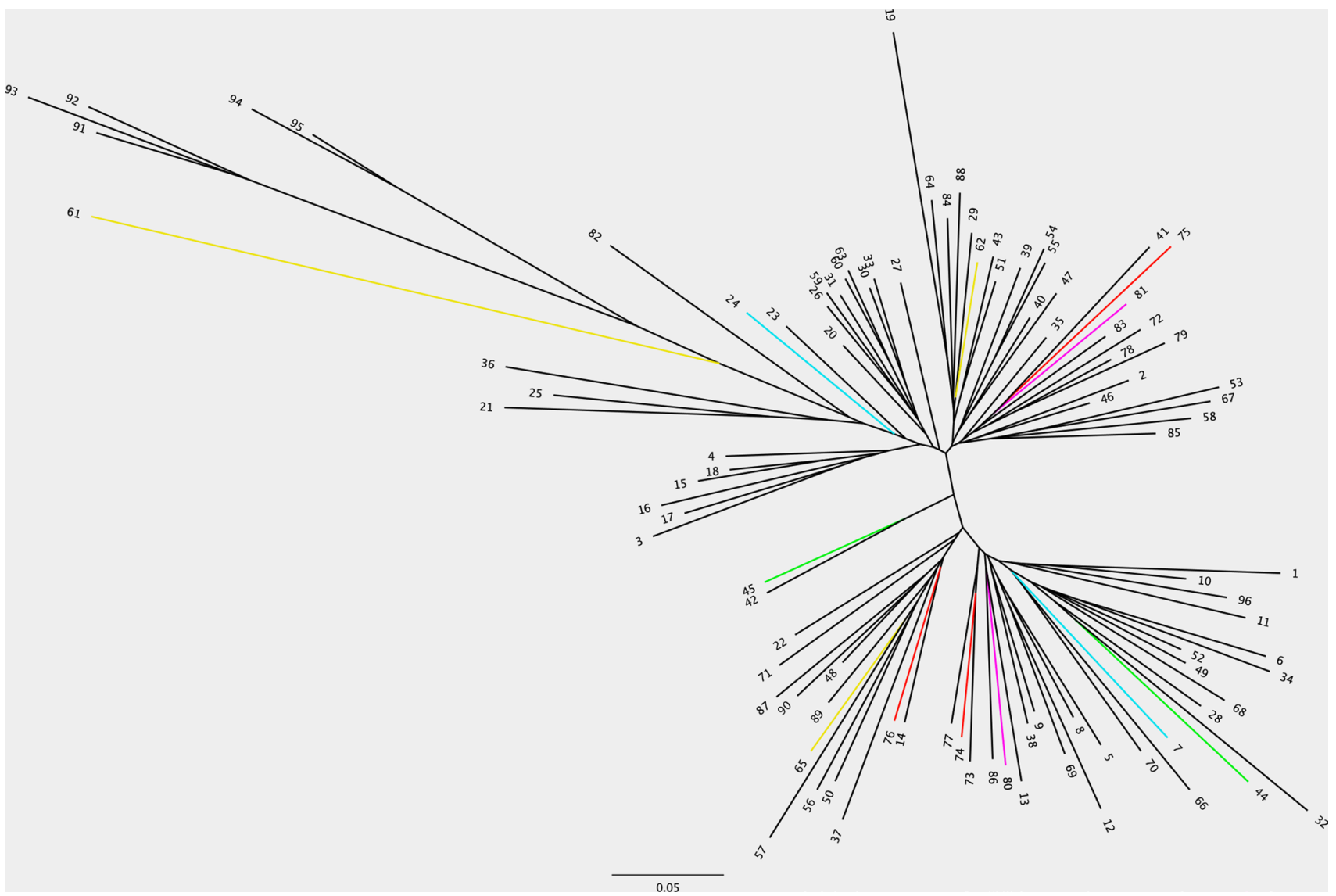

Fig. 6 Neighbour joining (NJ) tree showing phylo-epigenetic differences between EAHB cultivar clones, EAHB clone variants and EAHB lineage clones raised in same field or in different fields; numbers in black at the tips of branches relate to cultivars listed in Supplementary Table 1

genetic uniformity of the EAHB genepool, there is significant phenotypic diversity amongst the many farmer-selected landrace cultivars that dominate the Great Lakes region of East Africa. Such phenotypic diversity has prompted the establishment of germplasm collections and also the consideration of the Great Lakes region as a secondary centre of banana diversity (Tugume et al. 2002).

Based on 73 morphological traits, the EAHBs have been classified into groups (referred to as clone sets) to reflect their variation in vegetative structures, bunch, fruit and male bud. These are Nfuuka, Nakitembe, Musakala and Nakabululu (Karamura 1998). Sometimes cultivars of the cooking type become astringent and are no longer used for cooking but instead for making beer. These are referred to as Mbidde (Kitavi et al. 2016). As all farmer landraces of EAHBs have arisen from a single ancestral clone by vegetative (clonal) propagation, the extant phenotypic diversity of EAHBs may have arisen from rare somatic genetic mutations, mitotically heritable epigenetic modifications and/or genotype-byenvironment interactions. In particular, the observation that EAHB types can transition over time from one morphotype to another (e.g. from a cooking banana to a beer banana) is suggestive of epigenetic changes underpinning such transitions, particularly where there is no geographic movement of the EAHB vegetative lineage.

In this follow-on study from Kitavi et al. (2016), we have used methylation-sensitive AFLP (MSAP) to analyse the DNA methylation patterns across 90 EAHB cultivars from both the Ugandan and Kenyan germplasm collections, and determined the fidelity of the inheritance of the DNA methylation marks across generations in clonal versus sexual lineages. The EAHB germplasm population analysed show high levels of genomic DNA methylation at 5'-CCGG-3' sites. The proportion of CG methylation, which occurred at all $\mathrm{mCmCGG}$ and $\mathrm{CmCGG}$ sites, and a proportion of the indeterminate ones, was higher than the levels of $\mathrm{CHG}$ methylation. This pattern has also been observed in other plant genomes (Candaele et al. 2014; Lister et al. 2008; Osabe et al. 2014), although we note that CHG in EAHB still appears to be higher than in species such as Arabidopsis thaliana (Law and Jacobsen 2010). Notably, our phylogenetic approaches and structure analysis indicate that the Kenyan and Ugandan EAHB varieties cluster together, demonstrating that there are strong associations between DNA 

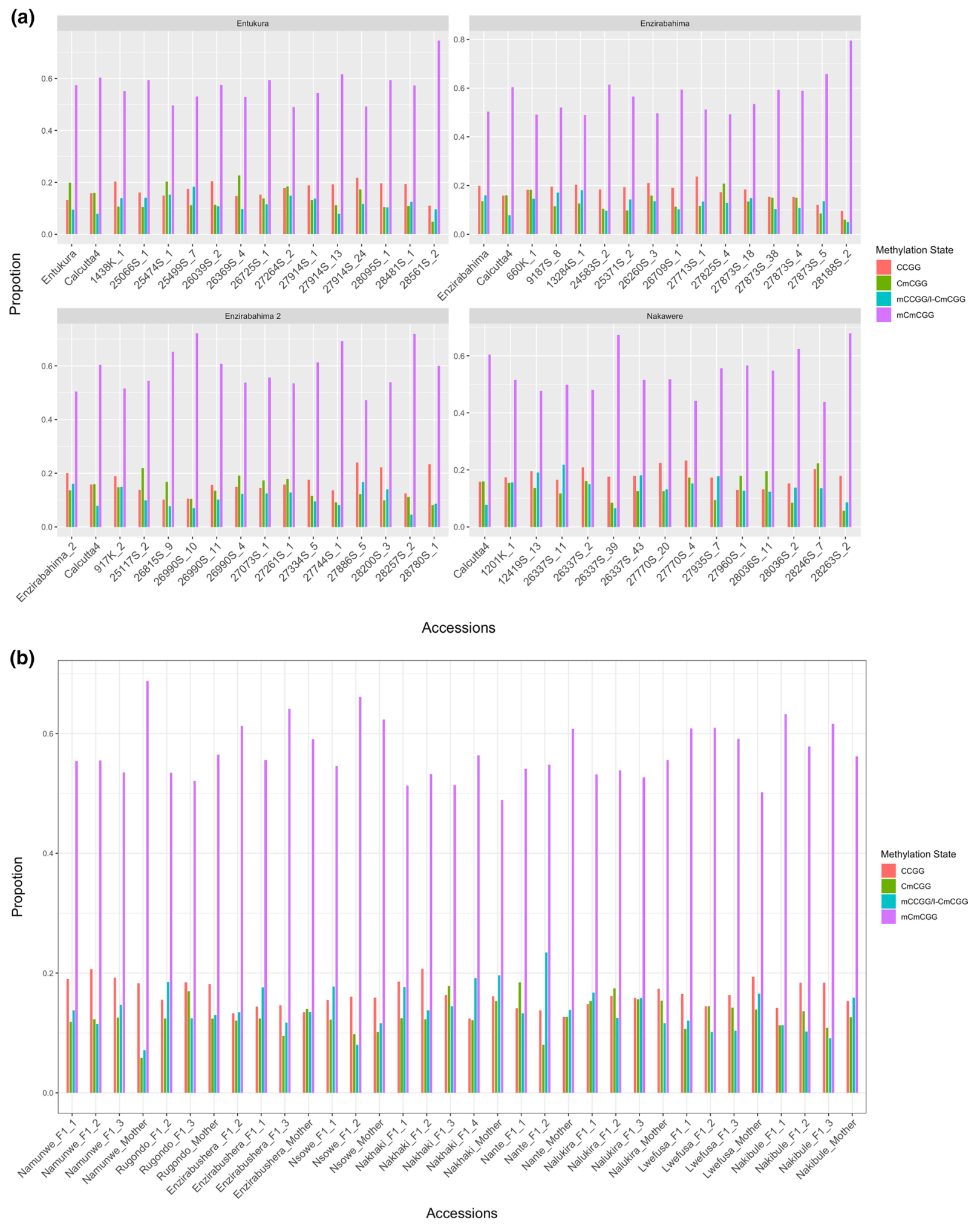

Fig. 7 Mean percentage of CCGG methylation states sites at 1868 loci assessed across a four sexual families, comprising $F_{0}$ (parents), $F_{1} \mathrm{~S}$ (tetraploids from a cross between wild calcutta4 and maternal landrace triploid EAHB) and $F_{2}$ s hybrids (triploids derived from a cross of a tetraploids with improved male diploids) and $\mathbf{b}$ asexual families represented by the mother plant and first cycle clonal plantlets derived through sucker vegetative propagation 
methylation patterns (epigenotypes) and the geographic areas they are sampled from.

The DNA methylation patterns of the EAHBs did not show any correlation to the morphological groups that are used to classify the EAHB germplasm collections. The lack of association could be due to the sample size ( 90 cultivars) or number of MSAP markers applied, or indeed indicate that there is no relationship between morphology-based classification and DNA methylation-based classification of the EAHBs. A more extensive epiGWAS analysis involving higher density epimarkers, greater numbers of EAHB clones, assessment of the morphological traits in terms of continuous variables instead of categorical morphotypes and large-scale reciprocal transplant studies would be needed to determine whether there is any significant association between epigenetic markers and the 73 traits that are used to classify EAHBs into the four morphotype clone sets. It is also important to note that DNA methylation is only one type of epigenetic mark, albeit a form of epigenetic mark that can be inherited mitotically or meiotically. While possible associations of the different clone groups with different histone modifications could be investigated, in the near term the DNA methylation polymorphism in EAHBs revealed in this study can provide an initial basis for epigenome based breeding for crops such as EAHBs which have limited genetic diversity, with further potential to develop epimarkers that are linked to traits of interest (Gallusci et al. 2017; Spillane and McKeown 2014; Springer 2013).

\section{Epigenetic differentiation of EAHB cultivars and morphotypes}

The differentiation of methylation polymorphisms across the EAHB populations, together with the stability of methylation patterns over generations (vegetative or seed derived) within specific EAHB cultivars, suggests that epigenotypes of EAHBs may be subject to environmental and farmer selection effects. Any functional effects of epigenetic modifications over multiple generations will depend on what traits are affected by specific epigenetic modifications (Preite et al. 2018). Indeed, a stronger role for epigenetic variation contributing to morphological variation and environmental adaptation of plants is emerging (Furci et al. 2019; Kooke et al. 2015, 2019; Zhang et al. 2013, 2018), including for clonal plants, such as those which reproduce apomictically (de Carvalho et al. 2016; Sailer et al. 2016; Wilschut et al. 2016). Our study demonstrates that DNA methylation diversity is high in EAHB genotypes grown in the same environment over generations. Similar results have been reported in other cultivated plants, which could be suggestive of epigenetic variation compensating for lack of genetic variation (Osabe et al. 2014; Riddle and Richards 2005).

\section{Heritability and conservation of epigenetic diversity in East African Highland bananas}

We observed a stable level of methylation states in the $F_{1} \mathrm{~s}$ (tetraploids) and $F_{2}$ (triploids) in the sexual families compared with their parents, though loci differed greatly across progeny (Fig. 9). Our results indicate that sexually generated offspring of EAHBs generated through meiotic crosses in the breeding programme can transmit at least some of the DNA methylation patterns of the parental plants. In the instances where DNA methylation is linked to functional traits of interest to the EAHB breeding programme, these findings suggest that either functional epimutations or epimarkers associated with epigenetically derived traits could be integrated into the EAHB breeding programme.

Plant genetic resources conservation has transitioned over time from conservation of germplasm accessions that maximise diversity of morphological, to the incorporation of data on genetic diversity (i.e. from molecular markers) so that germplasm collections that maximize evolutionary history in a manageable number of accessions can be constructed. While the rationale for such approaches is sound, the emerging likelihood that epigenetic variants may exist in
Table 2 Methylation level and status in meiotic families versus the vegetative clones. Number and frequency of variant methylation patterns, Shannon's Diversity Index $(I)$ and $\varphi$-ST of methylation susceptible loci (MSL) and nonmethylation susceptible loci (NML) in sexual and asexual vegetatively propagated EAHB groups across 1805 loci

\begin{tabular}{lll}
\hline Index & Sexual families & Asexual families \\
\hline Number of samples/individuals & 60 & 34 \\
Number of groups/populations & 6 & 9 \\
Number of methylation-susceptible loci (MSL) & 1837 & 1830 \\
Number of non-methylated loci (NML) & 31 & 38 \\
Number of polymorphic MSL & $1558(85 \%$ of 1668$)$ & $1347(74 \%$ of 1830$)$ \\
Number of polymorphic NML & $31(100 \%$ of 31$)$ & $33(87 \% 38)$ \\
Shannon's Diversity Index $(I)$ MSL & $0.3611(\mathrm{SD} ; 0.1994)$ & $0.3612(\mathrm{SD} ; 0.1919)$ \\
Shannon's Diversity Index $(I)$ NML & $0.1888(\mathrm{SD} ; 0.0737)$ & $0.2110(\mathrm{SD} ; 0.0672)$ \\
$\varphi$-ST MSL & $0.03968(P<0.0001)$ & $0.0921(P<0.0001)$ \\
$\varphi$-ST NML & $0.06185(P=0.0266)$ & $0.0502(P=0.051)$ \\
Mantel $(r)$ correlation of MSL/NML & $0.1302(P=0.0899)$ & $0.3129(P=0.003)$ \\
\hline
\end{tabular}



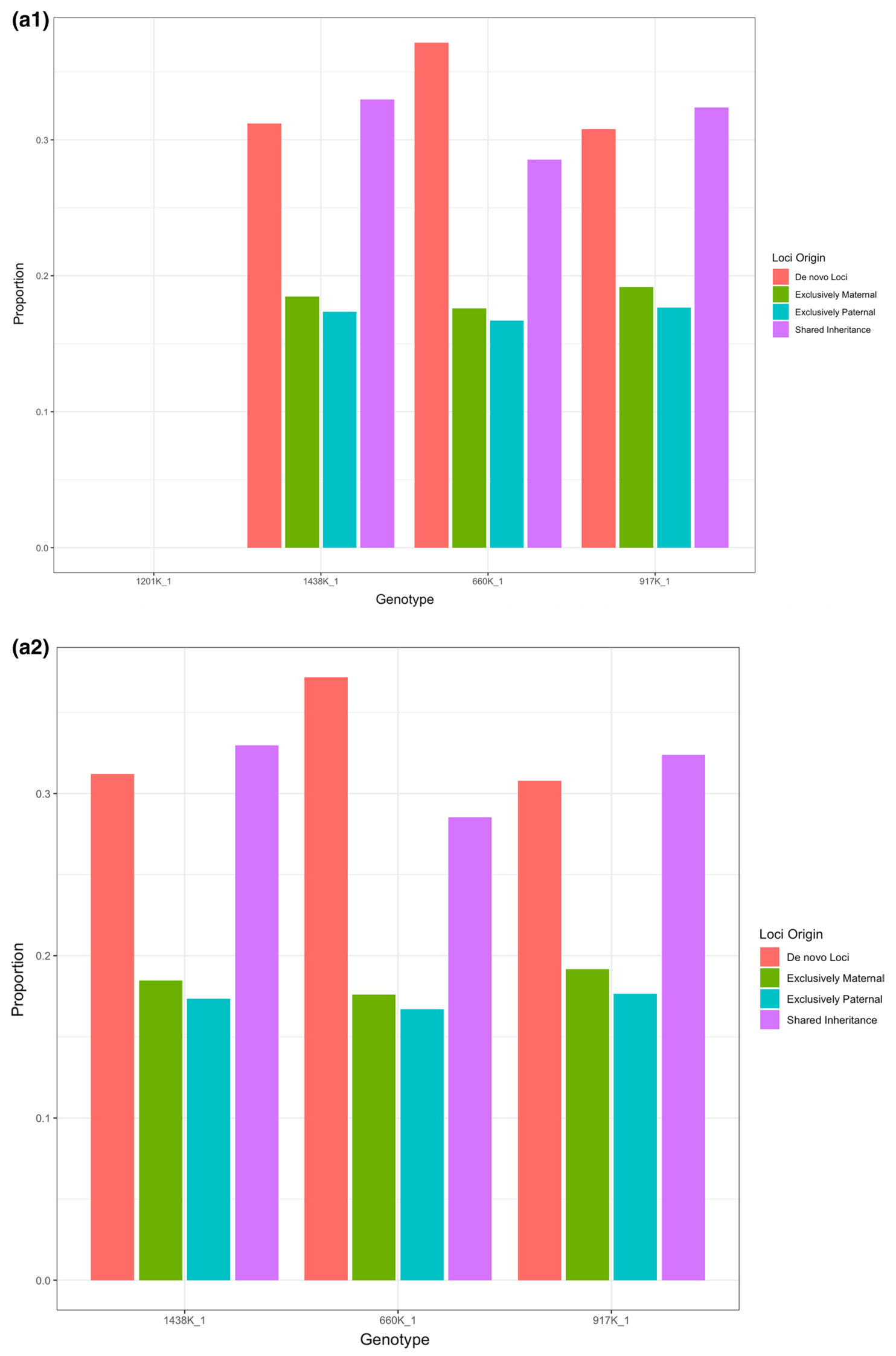

Fig. 8 Total number of loci inherited by a the tetraploid $F_{1} \mathrm{~s}(1438-1,660 \mathrm{~K}-1,917 \mathrm{~K}-2$ and $1201 \mathrm{~K}-1)$ from the $F_{0}$ generation and b the triploid $F_{2}$ s from the $F_{1}$ generation in sexual families in terms of locus origin 


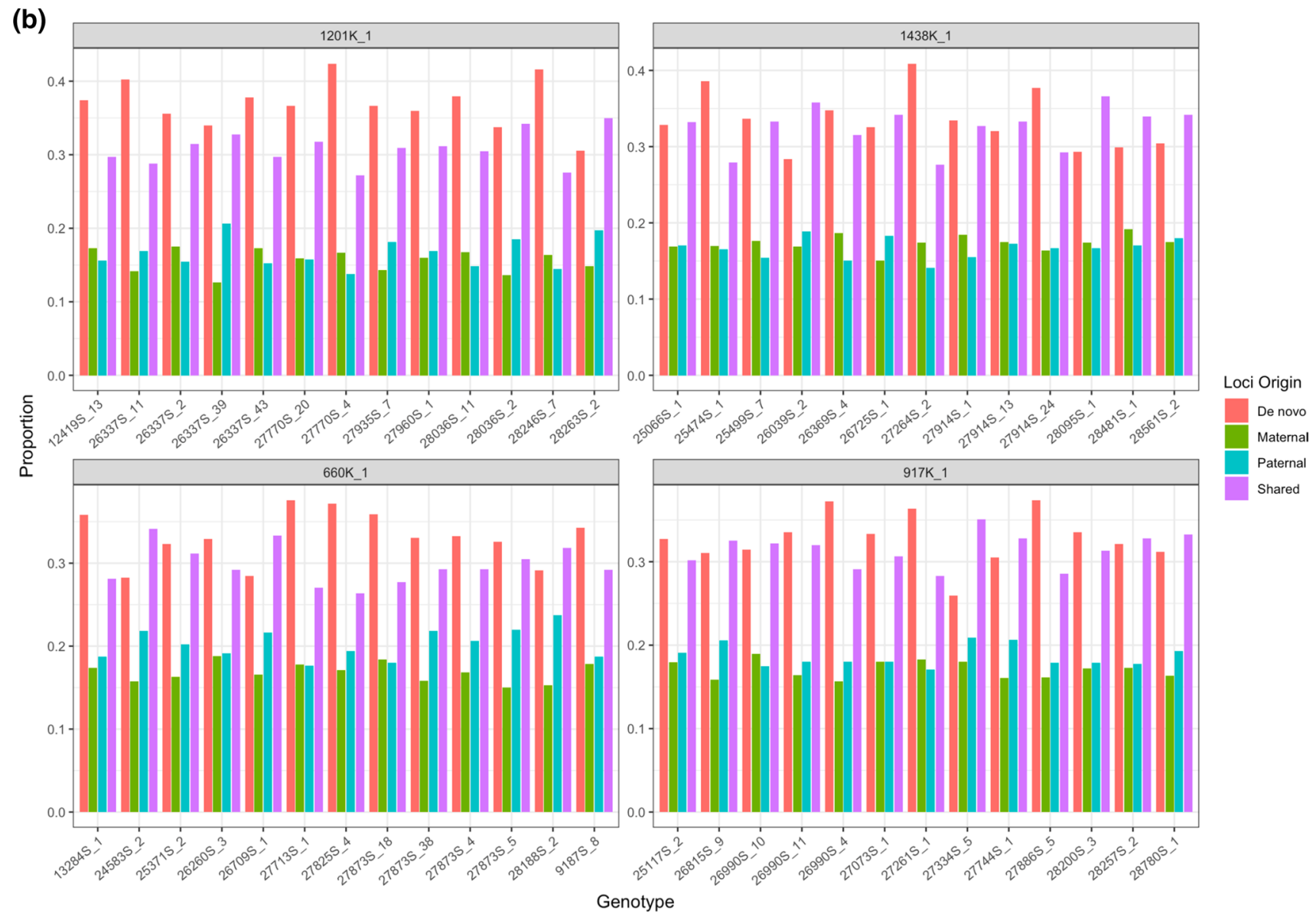

Fig. 8 (continued)

crop genepools that are of functional or agronomic importance provides a rationale for conservation of epigenotypes of importance to the crop's biology, breeding efforts and the performance of cultivars in agricultural systems. Our results point towards location as a large contributor of the EAHB epigenome state, and as such ensuring epigenomes included in conservation efforts are sampled from a meaningful or diverse environment types could be important for maximizing epigenetic diversity conservation and sustainable use efforts.

In particular, we consider that the phenotypic diversity of clonal crops such as EAHBs or other allopolyploid crops, which have undergone severe genetic bottlenecks can have limited genetic diversity in their genepools, may be underpinned by heritable epimutations of agronomic importance. These may be meiotically or mitotically transmissible, depending on the propagation biology of the crop. Our results highlight that, in contrast to genetic diversity, there is significant DNA methylation diversity that has arisen between the EAHB varieties that have all arisen via vegetative propagation from a single ancestral clone. Moreover, our comparisons of asexual versus sexual reproduction of EAHBs indicate that DNA methylation heritability and dynamics between parent and offspring can be substantial, providing ample basis for the emergence of epigenotypes selected by environment and/or farmers (where epialleles are contributing to functionally important traits). While genetic similarity can be used as a basis to reduce numbers of accessions in germplasm collections, our results highlight that epigenome profiling of accessions can differentiate epigenotypes that should be retained in germplasm collections on the basis that they may harbour epialleles contributing to traits of importance to the agronomy and quality characteristics of the crop. 


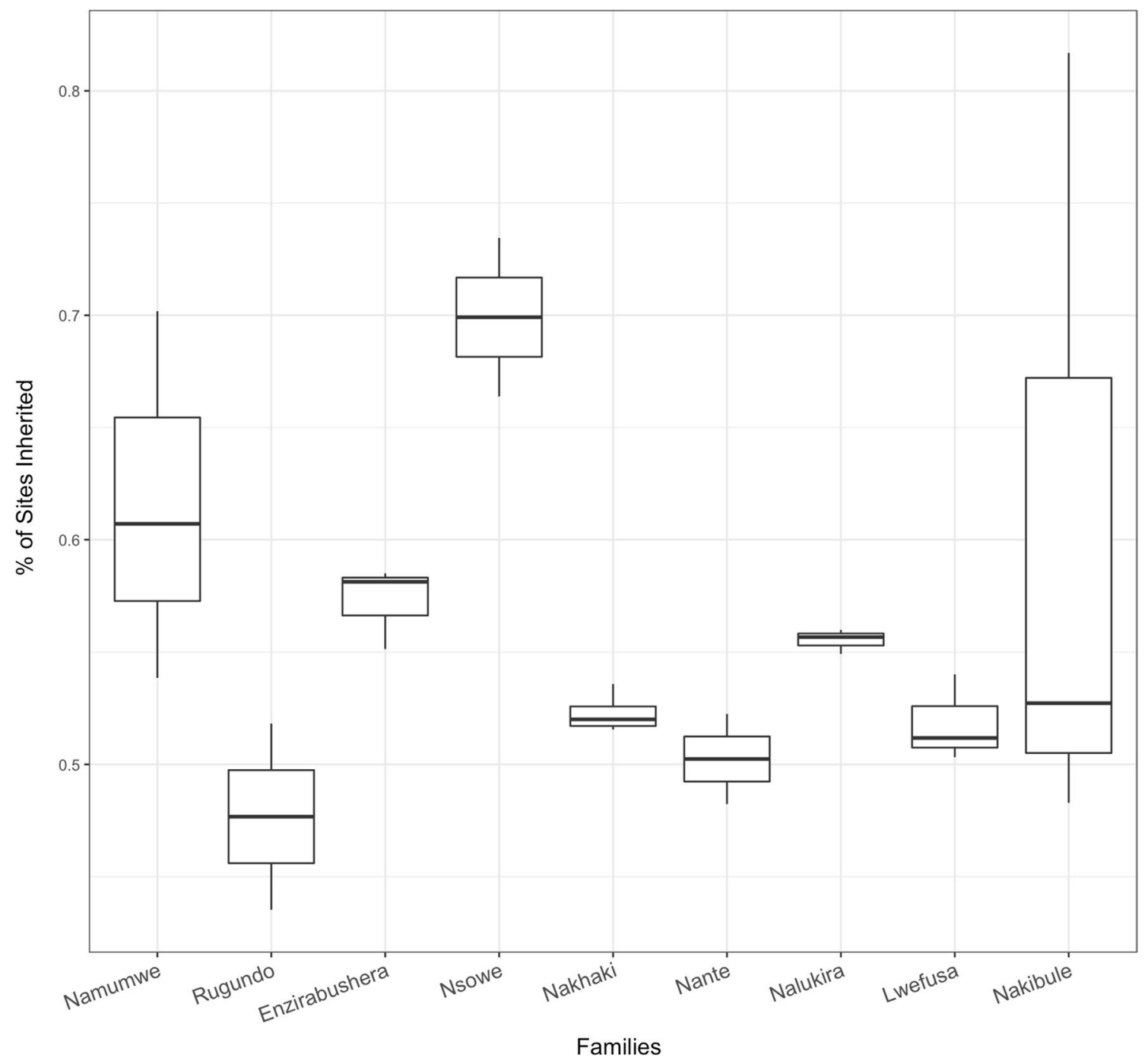

Fig. 9 Comparison of inheritance of CCGG site methylation state between sucker/plantlet clones families derived from nine different mother plants (in the asexual (vegetative) families 7-15; Supplementary Fig.1). $Y$-axis represents the proportion of loci which match the mother plant

\section{Conclusions}

Clonal crops that are vegetatively propagated have the potential for emergence of new variants due to genetic or epigenetic mutations. Some clonal crops (especially triploids or allopolyploids) have undergone severe genetic bottlenecks during their domestication and cultivation history. EAHBs present an excellent example of a clonal crop that has undergone such a genetic bottleneck, as the EAHB genepool is genetically uniform arising from vegetative propagation 'lineages' from a single ancestral clone. Our results highlight that crops such as EAHBs can have genetically uniform yet morphologically diverse morphotypes (varieties) that display considerable epigenetic variation across epigenotypes and between parents and offspring. While our experiments do not demonstrate causality between epigenotypes and morphotypes, or between epialleles and traits, our results do highlight that epigenetic variation can provide a basis for conservation of morphologically distinct, yet morphologically diverse accessions in plant epigenetic conservation programmes. In addition, our results provide a foundational basis for the integration of DNA methylation profiling for germplasm conservation and harnessing epigenetics in breeding programmes for East African Highland bananas. 
Table 3 Pairwise comparison of shared loci between the $F_{0}$ and $F_{1}$ in terms of family and methylation state: All values are $P$ values from Dunn's test of multiple comparison

\begin{tabular}{lllll}
\hline Comparison & $F_{0} \mathrm{M}$ & $F_{0} \mathrm{P}$ & $F_{0} \mathrm{M}+\mathrm{P}$ & $F_{1}$ \\
\hline Entukura-Enzirabahima 1 & $1.0000(+/-)$ & $1.0000(+/-)$ & $0.6072(+/-)$ & $0.0558(-/+)$ \\
Entukura-Enzirabahima 2 & $1.0000(+/-)$ & $1.0000(+/-)$ & $0.8655(+/-)$ & $0.1551(-/+)$ \\
Enzirabahima 1-Enzirabahima 2 & $1.0000(+/-)$ & $1.0000(-/+)$ & $0.8655(-/+)$ & $0.5563(+/-)$ \\
mCmCGG-CCGG & $1.0000(-/+)$ & $1.0000(+/-)$ & $0.5641(+/-)$ & $0.8462(-/+)$ \\
mCmCGG-CmCGG & $1.0000(-/+)$ & $1.0000(-/+)$ & $0.1045(+/-)$ & $0.8712(-/+)$ \\
mCmCGG-mCCGG/i-CmCGG & $0.6775(-/+)$ & $1.0000(-/+)$ & $0.1177(+/-)$ & $1.0000(-/+)$ \\
CCGG-CmCGG & 1.0000 & $1.0000(-/+)$ & $1.0000(-/+)$ & $1.0000(+/-)$ \\
CCGG-mCCGG/i-CmCGG & $1.0000(-/+)$ & $0.9374(-/+)$ & $1.0000(+/-)$ & $1.0000(+/-)$ \\
CmCGG-mCCGG/i-CmCGG & $1.0000(-/+)$ & $1.0000(-/+)$ & $1.0000(-/+)$ & $1.0000(-/+)$ \\
\hline
\end{tabular}

$(+/-)$ indicates that a larger portion of the former group of the comparison is shared with the loci type in question than the latter, while $(-/+)$ indicates the reverse. $F_{0} \mathrm{M}-$ loci that match exclusively to the $F_{0}$ mother, $F_{0} \mathrm{P}$-loci that match exclusively to the $F_{0}$ father, $F_{0} \mathrm{M}+\mathrm{P}$-loci that match to both $F_{0}$ mother and $F_{0}$ father, $F_{1}$-de novo loci in the $F_{1}$ progeny

Table 4 Pairwise comparison of shared loci between the $F_{0}, F_{1}$ and $F_{2}$ in terms of family and methylation state: All values are $P$ values from Dunn's test of multiple comparison

\begin{tabular}{|c|c|c|c|c|c|c|}
\hline Comparison & $F_{0} \mathrm{M}$ & $F_{0} \mathrm{M}+\mathrm{P}$ & $F_{1} \mathrm{M}$ & $F_{1} \mathrm{P}$ & $F_{1} \mathrm{M}+\mathrm{P}$ & $F_{2}$ \\
\hline Entukura—Enzirabahima 1 & $0.2080(+/-)$ & $0.0132(+/-)$ & $>0.0001(-/+)$ & $0.4754(-/+)$ & $0.7861(+/-)$ & $1.0000(-/+)$ \\
\hline Entukura-Enzirabahima 2 & $0.0742(+/-)$ & $0.0917(+/-)$ & $0.0001(-/+)$ & $0.2598(-/+)$ & $0.7861(-/+)$ & $1.0000(+/-)$ \\
\hline Enzirabahima 1-Enzirabahima 2 & $0.5355(+/-)$ & $0.3949(-/+)$ & $0.0928(+/-)$ & $0.5941(-/+)$ & $0.5762(-/+)$ & $1.0000(+/-)$ \\
\hline $\mathrm{mCmCGG-CCGG}$ & $>0.0001(-/+)$ & $>0.0001(+/-)$ & $0.1353(+/-)$ & $>0.0001(-/+)$ & $>0.0001(+/-)$ & $0.0023(-/+)$ \\
\hline mCmCGG-CmCGG & $0.0659(-/+)$ & $>0.0001(+/-)$ & $0.7432(+/-)$ & $>0.0001(-/+)$ & $0.0094(+/-)$ & $\begin{array}{c}>0.0001 \\
(-/+)\end{array}$ \\
\hline mCmCGG-mCCGG/i-CmCGG & $0.0002(-/+)$ & $>0.0001(+/-)$ & $0.0403(+/-)$ & $0.0008(-/+)$ & $0.0283(+/-)$ & $\begin{array}{c}>0.0001 \\
(-/+)\end{array}$ \\
\hline CCGG-CmCGG & $>0.0001(+/-)$ & $0.0160(+/-)$ & $0.5635(-/+)$ & $0.7531(+/-)$ & $0.0083(-/+)$ & $0.0690(-/+)$ \\
\hline CCGG-mCCGG/i-CmCGG & $0.0005(+/-)$ & $0.4431(+/-)$ & $0.7432(+/-)$ & $0.1904(+/-)$ & $0.0017(-/+)$ & $0.1762(-/+)$ \\
\hline CmCGG-mCCGG/i-CmCGG & $0.0659(-/+)$ & $0.0868(-/+)$ & $0.2768(+/-)$ & $0.2465(+/-)$ & $0.6162(-/+)$ & $0.5703(+/-)$ \\
\hline
\end{tabular}

Numbers highlighted in bold indicate significant differences

$(+/-)$ indicates that a larger portion of the former group of the comparison is shared with the loci type in question than the latter, while $(-/+)$ indicates the reverse. $F_{0} \mathrm{M}$-loci that match to the $F_{0}$ mother and are present in the $F_{1}$ progeny, $F_{0} \mathrm{M}+\mathrm{P}-$ loci that match to both $F_{0}$ mother and $F_{0}$ father which are present in the $F_{1}$ progeny, $F_{1} \mathrm{M}-$ loci which were novel in the $F_{1}$ mother that are shared with the $F_{2}$ progeny, $F_{1} \mathrm{P}-$ loci which in the $F_{1}$ father that are shared with the $F_{2}$ progeny, $F_{1} \mathrm{M}+\mathrm{P}$-loci shared in the $F_{1}$ mother and $F_{1}$ father that are not shared with the $F_{0}$ parents, $F_{2}$-de novo loci in the $F_{2}$ progeny

Acknowledgements This work was supported by funding from Irish Aid to the International Institute for Tropical Agriculture (IITA) and by Science Foundation Ireland (SFI) Principal Investigator Grants 08/ IN.1/B193 and 13/IA/1820.

Author Contribution statement CS raised the funding for the research and managed the research project. CS and JL designed the research project. MK conducted the field and laboratory work. MF, MN and RS provided research advice and supports. MK, CS and JL drafted the manuscript which was revised by CS and PMK.

\section{Compliance with ethical standards}

Conflict of interest On behalf of all authors, the corresponding author states that there is no conflict of interest.
Open Access This article is licensed under a Creative Commons Attribution 4.0 International License, which permits use, sharing, adaptation, distribution and reproduction in any medium or format, as long as you give appropriate credit to the original author(s) and the source, provide a link to the Creative Commons licence, and indicate if changes were made. The images or other third party material in this article are included in the article's Creative Commons licence, unless indicated otherwise in a credit line to the material. If material is not included in the article's Creative Commons licence and your intended use is not permitted by statutory regulation or exceeds the permitted use, you will need to obtain permission directly from the copyright holder. To view a copy of this licence, visit http://creativecommons.org/licenses/by/4.0/. 


\section{References}

Batte M, Swennen R, Uwimana B, Akech V, Brown A, Tumuhimbise R, Hovmalm HP, Geleta M, Ortiz R (2019) Crossbreeding East African highland bananas: lessons learnt relevant to the botany of the crop after 21 years of genetic enhancement. Front Plant Sci 10:81

Brozynska M, Furtado A, Henry RJ (2016) Genomics of crop wild relatives: expanding the gene pool for crop improvement. Plant Biotechnol J 14:1070-1085

Caballero A, Quesada H (2010) Homoplasy and distribution of AFLP fragments: an analysis in silico of the genome of different species. Mol Biol Evol 27:1139-1151

Candaele J, Demuynck K, Mosoti D, Beemster GT, Inze D, Nelissen H (2014) Differential methylation during maize leaf growth targets developmentally regulated genes. Plant Physiol 164:1350-1364

Castañeda-Alvarez NP, Khoury CK, Achicanoy HA, Bernau V, Dempewolf H, Eastwood RJ, Guarino L, Harker RH, Jarvis A, Maxted $\mathrm{N}$ (2016) Global conservation priorities for crop wild relatives. Nat Plants 2:16022

Cooper HD, Spillane C, Hodgkin T (2001) Broadening the genetic base of crop production. CABI, Wallingford

Cortijo S, Wardenaar R, Colomé-Tatché M, Gilly A, Etcheverry M, Labadie K, Caillieux E, Aury J-M, Wincker P, Roudier F (2014) Mapping the epigenetic basis of complex traits. Science (New York, NY) 343:1145-1148

Cubas P, Vincent C, Coen E (1999) An epigenetic mutation responsible for natural variation in floral symmetry. Nature 401:157-161

de Carvalho JF, Oplaat C, Pappas N, Derks M, de Ridder D, Verhoeven KJ (2016) Heritable gene expression differences between apomictic clone members in Taraxacum officinale: insights into early stages of evolutionary divergence in asexual plants. BMC Genomics 17:203

De Langhe E, Laliberte B, Chase R, Domaingue R, Horry J-P, Karamura D, Rouard M, Ruas M, Sardos J, Thomas J (2016) The 2016 Global Strategy for the conservation and use of Musa genetic resources-key strategic elements. In: $X$ international symposium on Banana: ISHS-ProMusa symposium on agroecological approaches to promote innovative Banana 1196, pp 71-78

Dellaporta SL, Wood J, Hicks JB (1983) A plant DNA minipreparation: Version II. Plant Mol Biol Rep 1(4):19-21

Eichten SR, Swanson-Wagner RA, Schnable JC, Waters AJ, Hermanson PJ, Liu S, Yeh CT, Jia Y, Gendler K, Freeling M, Schnable PS, Vaughn MW, Springer NM (2011) Heritable epigenetic variation among maize inbreds. PLoS Genet 7:e1002372

Engelmann F (2011) Use of biotechnologies for the conservation of plant biodiversity. Vitro Cell Dev Biol Plant 47:5-16

Evanno G, Regnaut S, Goudet J (2005) Detecting the number of clusters of individuals using the software structure: a simulation study. Mol Ecol 14:2611-2620

Fulneček J, Kovařík A (2014) How to interpret methylation sensitive amplified polymorphism (MSAP) profiles? BMC Genet 15:1-9

Furci L, Jain R, Stassen J, Berkowitz O, Whelan J, Roquis D, Baillet V, Colot V, Johannes F, Ton J (2019) Identification and characterisation of hypomethylated DNA loci controlling quantitative resistance in Arabidopsis. eLife 8:e40655

Gallusci P, Dai Z, Génard M, Gauffretau A, Leblanc-Fournier N, Richard-Molard C, Vile D, Brunel-Muguet S (2017) Epigenetics for plant improvement: current knowledge and modeling avenues. Trends Plant Sci 22:610-623

Grossniklaus U, Kelly WG, Ferguson-Smith AC, Pembrey M, Lindquist S (2013) Transgenerational epigenetic inheritance: how important is it? Nat Rev Genet 14:228

Halewood M, Chiurugwi T, Sackville Hamilton R, Kurtz B, Marden E, Welch E, Michiels F, Mozafari J, Sabran M, Patron N (2018)
Plant genetic resources for food and agriculture: opportunities and challenges emerging from the science and information technology revolution. New Phytol 217:1407-1419

Hamilton AC, Karamura D, Kakudidi E (2016) History and conservation of wild and cultivated plant diversity in Uganda: forest species and banana varieties as case studies. Plant Divers 38:23-44

He XJ, Chen T, Zhu JK (2011) Regulation and function of DNA methylation in plants and animals. Cell Res 21:442-465

Holland BR, Clarke AC, Meudt HM (2008) Optimizing automated AFLP scoring parameters to improve phylogenetic resolution. Syst Biol 57:347-366

Kaeppler SM, Kaeppler HF, Rhee Y (2000) Epigenetic aspects of somaclonal variation in plants. In: Matzke MA, Matzke AJM (eds) Plant gene silencing. Springer, Dordrecht, pp 59-68

Keyte AL, Percifield R, Liu B, Wendel JF (2006) Infraspecific DNA methylation polymorphism in cotton(Gossypium hirsutum L.). J Hered 97(5):444-450

Kitavi M, Downing T, Lorenzen J, Karamura D, Onyango M, Nyine M, Ferguson M, Spillane C (2016) The triploid East African Highland Banana (EAHB) genepool is genetically uniform arising from a single ancestral clone that underwent population expansion by vegetative propagation. Theor Appl Genet 129:547-561

Kooke R, Johannes F, Wardenaar R, Becker F, Etcheverry M, Colot V, Vreugdenhil D, Keurentjes JJ (2015) Epigenetic basis of morphological variation and phenotypic plasticity in Arabidopsis thaliana. Plant Cell 27:337-348

Kooke R, Morgado L, Becker F, van Eekelen H, Hazarika R, Zheng Q, de Vos RC, Johannes F, Keurentjes JJ (2019) Epigenetic mapping of the Arabidopsis metabolome reveals mediators of the epigenotype-phenotype map. Genome Res 29:96-106

Law JA, Jacobsen SE (2010) Establishing, maintaining and modifying DNA methylation patterns in plants and animals. Nat Rev Genet 11:204-220

Lerceteau-Kohler E, Schliewen U, Kopun T, Weiss S (2013) Genetic variation in brown trout Salmo trutta across the Danube, Rhine, and Elbe headwaters: a failure of the phylogeographic paradigm? BMC Evol Biol 13:176

Lira-Medeiros C, Parisod C, Fernandes RA, Mata CS, Cardoso MA, Ferreira PCG (2010) Epigenetic variation in mangrove plants occurring in contrasting natural environment. PLoS ONE 5(4):e10326

Lister R, O'Malley RC, Tonti-Filippini J, Gregory BD, Berry CC, Millar AH, Ecker JR (2008) Highly integrated single-base resolution maps of the epigenome in Arabidopsis. Cell 133:523-536

Liu S, Sun K, Jiang T, Ho JP, Liu B, Feng J (2012) Natural epigenetic variation in the female great roundleaf bat (Hipposideros armiger) populations. Mol Genet Genomics MGG 287:643-650

Lunerova-Bedrichova J, Bleys A, Fojtova M, Khaitova L, Depicker A, Kovarik A (2008) Trans-generation inheritance of methylation patterns in a tobacco transgene following a post-transcriptional silencing event. Plant J Cell Mol Biol 54:1049-1062

Mace ES, Buhariwalla KK, Buhariwalla HK, Crouch JH (2003) A high-throughput DNA extraction protocol for tropical molecular breeding programs. Plant Mol Biol Rep 21(4):459-460

Markert JA, Champlin DM, Gutjahr-Gobell R, Grear JS, Kuhn A, McGreevy TJ Jr, Roth A, Bagley MJ, Nacci DE (2010) Population genetic diversity and fitness in multiple environments. BMC Evol Biol 10:205

McKeown PC, Spillane C (2014) Landscaping plant epigenetics. In: Spillane C, McKeown P (eds) Plant epigenetics and epigenomics. Springer, Berlin, pp 1-24

Morgado L, Preite V, Oplaat C, Anava S, Ferreira de Carvalho J, Rechavi O, Johannes F, Verhoeven KJ (2017) Small RNAs reflect grandparental environments in apomictic dandelion. Mol Biol Evol 34:2035-2040 
Němečková A, Christelová P, Čížková J, Nyine M, Svačina R, Uwimana B, Swennen R, Doležel J, Hribova E (2018) Molecular and cytogenetic study of east African highland banana. Front Plant Sci 9:1371

Osabe K, Clement JD, Bedon F, Pettolino FA, Ziolkowski L, Llewellyn DJ, Finnegan EJ, Wilson IW (2014) Genetic and DNA methylation changes in cotton (Gossypium) genotypes and tissues. PLoS ONE 9:e86049

Parisod C, Christin P-A (2008) Genome-wide association to finescale ecological heterogeneity within a continuous population of Biscutella laevigata (Brassicaceae). New Phytol 178:436-447

Paszkowski J, Grossniklaus U (2011) Selected aspects of transgenerational epigenetic inheritance and resetting in plants. Curr Opin Plant Biol 14:195-203

Pérez-Figueroa A (2013) MSAP: a tool for the statistical analysis of methylation-sensitive amplified polymorphism data. Mol Ecol Resour 13:522-527

Preite V, Oplaat C, Biere A, Kirschner J, van der Putten WH, Verhoeven KJ (2018) Increased transgenerational epigenetic variation, but not predictable epigenetic variants, after environmental exposure in two apomictic dandelion lineages. Ecol Evol 8:3047-3059

Pritchard J, Stephens M, Donnelly P (2000) Inference of population structure using multilocus genotype data. Genetics 155:945-959

Pritchard J, Wen X, Falush D (2010) Documentation for structure software: version 2.3. Department of Statistics, University of Oxford, Oxford

Quadrana L, Colot V (2016) Plant transgenerational epigenetics. Annu Rev Genet 50:467-491

Rebetzke G, Jimenez-Berni J, Fischer R, Deery D, Smith D (2018) High-throughput phenotyping to enhance the use of crop genetic resources. Plant Sci 282:40-48

Riddle NC, Richards EJ (2005) Genetic variation in epigenetic inheritance of ribosomal RNA gene methylation in Arabidopsis. Plant J 41:524-532

Sailer C, Schmid B, Grossniklaus U (2016) Apomixis allows the transgenerational fixation of phenotypes in hybrid plants. Curr Biol 26:331-337

Saze H, Scheid OM, Paszkowski J (2003) Maintenance of CpG methylation is essential for epigenetic inheritance during plant gametogenesis. Nat Genet 34:65

Shannon CE (1948) A mathematical theory of communication. Bell Syst Tech J 27(3):379-423
Spillane C, Gepts P (2001) Evolutionary and genetic perspectives on the dynamics of crop genepools. In: Cooper HD, Spillane C, Hodgkin T (eds) Broadening the genetic base of crop production. CABI International, IPGRI and FAO, Oxford, pp 25-70

Spillane C, McKeown PC (2014) Plant epigenetics and epigenomics. Springer, Berlin

Springer NM (2013) Epigenetics and crop improvement. Trends Genet 29:241-247

Thioulouse J, Chessel D, Dole S, Olivier JM (1997) ADE-4: a multivariate analysis and graphical display software. Stat Comput 7(1):75-83

Tugume A, Lubega G, Rubaihayo P (2002) Genetic diversity of East African Highland bananas using AFLP. Infomusa 11:28-32

van Hintum TJ, Brown AHD, Spillane C, Hodkin T (2000) Core collections of plant genetic resources. Bioversity International, Rome

Wendte JM, Schmitz RJ (2018) Specifications of targeting heterochromatin modifications in plants. Mol plant 11:381-387

Whitlock R, Hipperson H, Mannarelli M, Butlin RK, Burke T (2008) An objective, rapid and reproducible method for scoring AFLP peak-height data that minimizes genotyping error. Mol Ecol Resour 8:725-735

Wilschut RA, Oplaat C, Snoek LB, Kirschner J, Verhoeven KJ (2016) Natural epigenetic variation contributes to heritable flowering divergence in a widespread asexual dandelion lineage. Mol Ecol 25:1759-1768

Zhang YY, Fischer M, Colot V, Bossdorf O (2013) Epigenetic variation creates potential for evolution of plant phenotypic plasticity. New Phytol 197:314-322

Zhang Y-Y, Latzel V, Fischer M, Bossdorf O (2018) Understanding the evolutionary potential of epigenetic variation: a comparison of heritable phenotypic variation in epiRILs, RILs, and natural ecotypes of Arabidopsis thaliana. Heredity 121:257

Zheng X, Chen L, Xia H, Wei H, Lou Q, Li M, Li T, Luo L (2017) Transgenerational epimutations induced by multi-generation drought imposition mediate rice plant's adaptation to drought condition. Sci Rep 7:39843

Publisher's Note Springer Nature remains neutral with regard to jurisdictional claims in published maps and institutional affiliations. 